\title{
Volcanic ash detection with infrared limb sounding: MIPAS observations and radiative transfer simulations
}

\author{
S. Griessbach ${ }^{1}$, L. Hoffmann ${ }^{1}$, R. Spang ${ }^{2}$, and M. Riese ${ }^{2}$ \\ ${ }^{1}$ Jülich Supercomputing Centre (JSC), Forschungszentrum Jülich GmbH, 52428 Jülich, Germany \\ ${ }^{2}$ Institute of Energy and Climate Research (IEK-7), Forschungszentrum Jülich GmbH, 52428 Jülich, Germany \\ Correspondence to: S. Griessbach (s.griessbach@fz-juelich.de)
}

Received: 24 October 2013 - Published in Atmos. Meas. Tech. Discuss.: 15 November 2013

Revised: 25 March 2014 - Accepted: 11 April 2014 - Published: 28 May 2014

\begin{abstract}
Small volcanic ash particles have long residence times in the troposphere and the stratosphere so that they have significant impact on the Earth's radiative budget and consequently affect climate. For global long-term observations of volcanic aerosol, infrared limb measurements provide excellent coverage, sensitivity to thin aerosol layers, and altitude information. The optical properties of volcanic ash and ice particles, derived from micro-physical properties, have opposing spectral gradients between 700 and $960 \mathrm{~cm}^{-1}$ for small particle sizes. Radiative transfer simulations that account for single scattering showed that the opposing spectral gradients directly transfer to infrared limb spectra. Indeed, we found the characteristic spectral signature, expected for volcanic ash, in measurements of the Michelson Interferometer for Passive Atmospheric Sounding (MIPAS) after the eruption of the Chilean volcano Puyehue-Cordón Caulle in June 2011. From these measurements we derived an ash detection threshold function. The empirical ash detection threshold was confirmed in an extensive simulations study covering a wide range of atmospheric conditions, particle sizes and particle concentrations for ice, volcanic ash and sulfate aerosol. From the simulations we derived the upper detectable effective radius of $3.5 \mu \mathrm{m}$ and the detectable extinction coefficient range of $5 \times 10^{-3}$ to $1 \times 10^{-1} \mathrm{~km}^{-1}$. We also showed that this method is only sensitive to volcanic ash particles, but not to volcanic sulfate aerosol. This volcanic ash detection method for infrared limb measurements is a fast and reliable method and provides complementary information to existing satellite aerosol products.
\end{abstract}

\section{Introduction}

Particles with radii smaller than $2 \mu \mathrm{m}$ have long residence times of up to weeks in the troposphere (Murrow et al., 1980) and years, if injected into the stratosphere (Mossop, 1964). Because they are efficient scatterers of ultraviolet and infrared radiation (Pueschel et al., 1994) as well as good absorbers in the infrared, they change the aerosol optical thickness in the atmosphere, affect the Earth's radiation budget, and hence have effects on climate. Volcanic eruptions can also be regarded as large atmospheric experiments, where a passive tracer, the volcanic ash, is injected from a point source. This volcanic ash can be used to observe atmospheric motion and to verify atmospheric transport models. For these reasons the global long-term detection of volcanic particles is of special interest to atmospheric and climate science. Furthermore, volcanic ash poses a severe danger to aircraft (e.g. Casadevall, 1994). Hence, for aviation safety near-real-time observations of volcanic ash plumes are essential.

Satellite measurements are best suited to provide global time series of volcanic ash observations. Infrared emission measurements are especially useful as they provide day and night observations. While infrared nadir measurements have a good horizontal resolution, infrared limb measurements give complementary altitude information.

For infrared nadir measurements the "reverse" absorption algorithm (Prata, 1989a, b) is a well-established technique for detecting volcanic ash clouds from infrared band measurements. It is improved and applied in several studies (e.g. Barton et al., 1992; Wen and Rose, 1994; Prata and Grant, 2001) and its limitations and challenges are discussed by Simpson et al. (2000) and Prata et al. (2001). For hyper-spectral instruments new methods are reported by 
Clarisse et al. (2010) and Gangale et al. (2010), which also rely on the characteristic spectral behaviour of volcanic ash and ice that is exploited by Prata (1989b).

Analyses of space-borne and balloon-borne infrared limb aerosol measurements focus on the detection of stratospheric volcanic sulfate aerosol, but do not aim at volcanic ash detection or cloud and aerosol classification in the upper troposphere. Stratospheric volcanic sulfate aerosol has been observed from space by the cryogenic limb array etalon spectrometer (CLAES) (Massie et al., 1996; Lambert et al., 1997) and the improved stratospheric and mesospheric sounder (ISAMS) (Grainger et al., 1993; Lambert et al., 1993), both aboard the Upper Atmospheric Research Satellite (UARS). Also the balloon-borne Michelson Interferometer for Passive Atmospheric Sounding (MIPAS-B) measured stratospheric volcanic sulfate aerosol during a campaign in Kiruna in 1992 (Echle et al., 1998).

A cloud detection method for hyper-spectral infrared limb measurements was first reported by Spang et al. (2001) for the space-borne Cryogenic Infrared Spectrometers and Telescopes for the Atmosphere (CRISTA) (Offermann et al., 1999; Riese et al., 1999). The cloud index (CI) is defined as the radiance ratio between 792 and $832 \mathrm{~cm}^{-1}$ and allows the detection of clouds in the troposphere and stratosphere. Spang et al. (2004) adapted the CI to the space-borne Michelson Interferometer for Passive Atmospheric Sounding (MIPAS) aboard Envisat. Spang et al. (2008) showed that the CI is also suited for the cloud evaluation of the air-borne CRISTA - New Frontiers (CRISTA-NF) measurements. Sembhi et al. (2012) optimised the CI thresholds to also detect aerosol with MIPAS. Regarding the discrimination between different cloud and aerosol types, Spang and Remedios (2003), Spang et al. (2004, 2005), Höpfner et al. (2009), and Spang et al. (2012) have presented methods to distinguish between different types of polar stratospheric clouds (PSCs). Concerning volcanic emission detection with MIPAS, two studies were recently published: Griessbach et al. (2012) discussed a method that specifically allows for volcanic ash detection and Grainger et al. (2013) presented new methods for volcanic plume detection.

The purpose of this paper is to introduce a volcanic ash detection method for infrared limb instruments using MIPAS data. It starts with a short description of the model used for radiative transfer simulations and the MIPAS instrument in Sect. 2. Then, the volcanic ash detection method is presented in Sect. 3. First, we discuss the optical properties of ice and volcanic ash and present their impact on infrared limb spectra and the characteristic signal. Second, we derive the ash detection threshold from MIPAS measurements. In Sect. 4 follows a detailed scattering simulation study for clear air, ice, volcanic ash and sulfate aerosol to confirm the ash detection threshold and to identify the detectable particle size and extinction coefficient range. In Sect. 5 the limitations and the further potential of the ash detection method are discussed, the volcanic ash detections are related to the CI, and analogies and differences to the "reverse" absorption algorithm for nadir measurements are discussed. The conclusions follow in Sect. 6.

\section{Forward model and instrument description}

\subsection{JURASSIC}

The Jülich Rapid Spectral Simulation Code (JURASSIC) is a fast radiative transfer model for the mid-infrared spectral region (Hoffmann, 2006). It was used in several studies for the infrared limb sounders MIPAS (Hoffmann et al., 2005, 2008), CRISTA-NF (Hoffmann et al., 2009; Weigel et al., 2010), the Gimballed Limb Observer for Radiance Imaging of the Atmosphere (GLORIA) (Ungermann et al., 2010) and the nadir instrument Atmospheric Infrared Sounder (AIRS) (Hoffmann and Alexander, 2009; Grimsdell et al., 2010).

For fast simulations, it applies pre-calculated look-up tables of spectral emissivities and approximations to radiative transfer calculations, such as the emissivity growth approximation (EGA) (Weinreb and Neuendorffer, 1973; Gordley and Russell, 1981; Marshall et al., 1994) and the CurtisGodson approximation (CGA) (Curtis, 1952; Godson, 1953). The look-up tables were calculated with the Reference Forward Model (RFM) (Dudhia et al., 2002; Dudhia, 2013), which is an exact line-by-line model specifically developed for MIPAS. JURASSIC has been compared to the line-byline models RFM and the Karlsruhe Optimized and Precise Radiative transfer Algorithm (KOPRA) (Stiller, 2000; Stiller et al., 2002) for selected spectral windows and shows good agreement (Griessbach et al., 2013).

JURASSIC contains a scattering module that allows for radiative transfer simulations including single and multiple scattering on aerosol and cloud particles (Griessbach, 2012; Griessbach et al., 2013). The optical properties of the particles, extinction coefficient, scattering coefficient and phase function, required for the radiative transfer simulations with scattering, can either be calculated with a Mie code assuming spherical particles, or can be taken from databases for nonspherical particles. In this study, all particles are assumed to be spherical and distributed in a homogeneous cloud layer. The particle size distributions are described by mono- and multi-modal log-normal distributions,

$\frac{\mathrm{d} N(r)}{\mathrm{d} r}=\sum_{i=1}^{m} \frac{n_{i}}{\sqrt{2 \pi} \ln \sigma_{i} r} \exp \left[-\frac{\left(\ln r-\ln \mu_{i}\right)^{2}}{2\left(\ln \sigma_{i}\right)^{2}}\right]$,

where $\frac{\mathrm{d} N}{\mathrm{~d} r}$ is the concentration of particles per radius interval $[r, r+\mathrm{d} r]$ and the parameters $n_{i}, \sigma_{i}, \mu_{i}$ represent the total number concentration, the dimensionless distribution width and the median radius of the mode with index $i$, respectively. Aside from the particle size distribution, the complex refractive indices of the particles and the cloud top and bottom altitudes are required for the radiative transfer simulations including scattering. 
Table 1. Log-normal number size distribution parameters used for the calculation of optical properties shown in Fig. 1. The scattering radius is given at $826 \mathrm{~cm}^{-1}$.

\begin{tabular}{llllllll}
\hline Particle type & Mode & $n_{i}\left(\mathrm{~cm}^{-3}\right)$ & $\mu_{i}(\mu \mathrm{m})$ & $\sigma_{i}$ & $r_{\text {sca }}(\mu \mathrm{m})$ & $r_{\text {eff }}(\mu \mathrm{m})$ & Reference \\
\hline Volcanic ash & 1 & 2000.0 & 0.045 & 1.5 & 3.7 & 0.8 & Schumann et al. (2011) \\
& 2 & 10.0 & 0.225 & 1.6 & & & (Fig. 7) \\
Sub-visible cirrus & 1 & 1.4 & 0.75 & 2.0 & & & \\
Tropical cirrus & 1 & 0.032 & 3.6 & 1.6 & 7.0 & 6.3 & Iwasaki et al. (2007) \\
Sulfate aerosol & 1 & 340.0 & 81 & 1.8 & 190.6 & 191.2 & Tian et al. (2010) \\
(post-Pinatubo) & 2 & 5.0 & 0.49 & 1.75 & 0.76 & 0.29 & Deshler et al. (1992) \\
\hline
\end{tabular}

\subsection{MIPAS}

The Michelson Interferometer for Passive Atmospheric Sounding (MIPAS) (Fischer et al., 2008) is aboard ESA's Envisat that was launched in 2002 and quit service in April 2012. MIPAS measured high-resolution infrared limb radiance spectra in the range $685-2410 \mathrm{~cm}^{-1}(14.6-$ $4.15 \mu \mathrm{m})$ in five bands: band $\mathrm{A} 685-970 \mathrm{~cm}^{-1}$, band $\mathrm{AB}$ $1020-1170 \mathrm{~cm}^{-1}$, band B $1215-1500 \mathrm{~cm}^{-1}$, band C 1570 $1750 \mathrm{~cm}^{-1}$, band $\mathrm{D} 1820-2410 \mathrm{~cm}^{-1}$ at altitudes ranging from 6 to $172 \mathrm{~km}$ (Fischer et al., 2008). For band A, which is used in this study, the noise equivalent spectral radiance is $3 \times 10^{-4} \mathrm{~W}\left(\mathrm{~m}^{2} \mathrm{sr} \mathrm{cm}^{-1}\right)^{-1}$ for the full-resolution mode (Kleinert et al., 2007a) and $3 \times 10^{-4} \mathrm{~W}\left(\mathrm{~m}^{2} \mathrm{srcm}^{-1}\right)^{-1} / \sqrt{\frac{20}{8}}$ for the reduced-resolution mode (Kleinert et al., 2007b).

From 2002 to 2004 the nominal spectral sampling was $0.025 \mathrm{~cm}^{-1}$ and the tangent altitudes ranged from $6 \mathrm{~km}$ to $68 \mathrm{~km}$ at all latitudes in vertical steps of $3 \mathrm{~km}$ (below $42 \mathrm{~km}$ ) in the standard mode (Fischer et al., 2008). In 2005 the spectral sampling was reduced to $0.0625 \mathrm{~cm}^{-1}$ and the measurement geometry was adjusted so that below $20 \mathrm{~km}$ altitude the vertical steps are $1.5 \mathrm{~km}$ and the measurement grid follows the slope of the tropopause, i.e. the lowest tangent altitude is at about $10 \mathrm{~km}$ in the tropics and $6 \mathrm{~km}$ in the polar regions (Fischer et al., 2008). The vertical MIPAS field of view is about $3 \mathrm{~km}$. For retrieval of MIPAS measurements, it is often assumed to be trapezoidal with edge lengths of 2.8 and $4 \mathrm{~km}$ (Ridolfi et al., 2000; Hurley et al., 2011). The field of view at the tangent point extends about $3 \mathrm{~km}$ in the vertical direction and $30 \mathrm{~km}$ perpendicular to the line of sight. The dimension of the measurement volume along the line of sight is about $300 \mathrm{~km}$.

\section{Volcanic ash detection with MIPAS}

\subsection{From optical properties to infrared limb spectra}

Cloud and aerosol detection from infrared limb measurements works best in atmospheric windows, which have little impact from atmospheric trace gases (Spang et al., 2002). Following Spang et al. (2002), Höpfner and Emde (2005), Mendrok et al. (2007), Griessbach (2012), and Griessbach et al. (2012), we focus on the $825-830$ and $946-951 \mathrm{~cm}^{-1}$ windows in MIPAS band A. In these studies, it is shown that, compared to clear air conditions, the radiance increases substantially all over the spectrum, if clouds are present. The increased radiances are due to blackbody emissions by the particles themselves plus scattered radiance from all directions into the line of sight of the instrument. If scattering is considered, the radiance enhancement can be significantly larger than for the particles' blackbody emission alone.

A prerequisite to distinguish volcanic ash particles from ice clouds is that the optical properties of the particles behave differently in the selected windows. The optical properties, extinction coefficient $\left(\beta_{\mathrm{e}}\right)$ and single-scattering albedo depend on complex refractive index, particle size, particle shape and wave number. The real and imaginary parts of the complex refractive indices of ice (Warren and Brandt, 2008), volcanic ash (Volz, 1973), volcanic ash components (andesite, basalt, basaltic glass, and obsidian Pollack et al., 1973) and sulfate aerosol (Hummel et al., 1988) are shown in Fig. 1a and b for MIPAS band A. The spectral slope between both windows (grey regions) for the real as well as the imaginary part of the ice refractive index is the opposite to the spectral slope of volcanic ash and sulfate aerosol refractive indices. All volcanic ash components have a larger refractive index at $950 \mathrm{~cm}^{-1}$ than at $825 \mathrm{~cm}^{-1}$, but the amplitude of this difference varies.

The particle sizes of ice clouds are highly variable and differ from the particle sizes of volcanic ash and sulfate aerosol. The calculated extinction coefficient spectra and single-scattering albedo spectra in Fig. 1c and d are derived from the complex refractive indices presented above and in situ measured particle size distributions given in Table 1 for volcanic ash, a sub-visible cirrus cloud (SVC), a tropical 

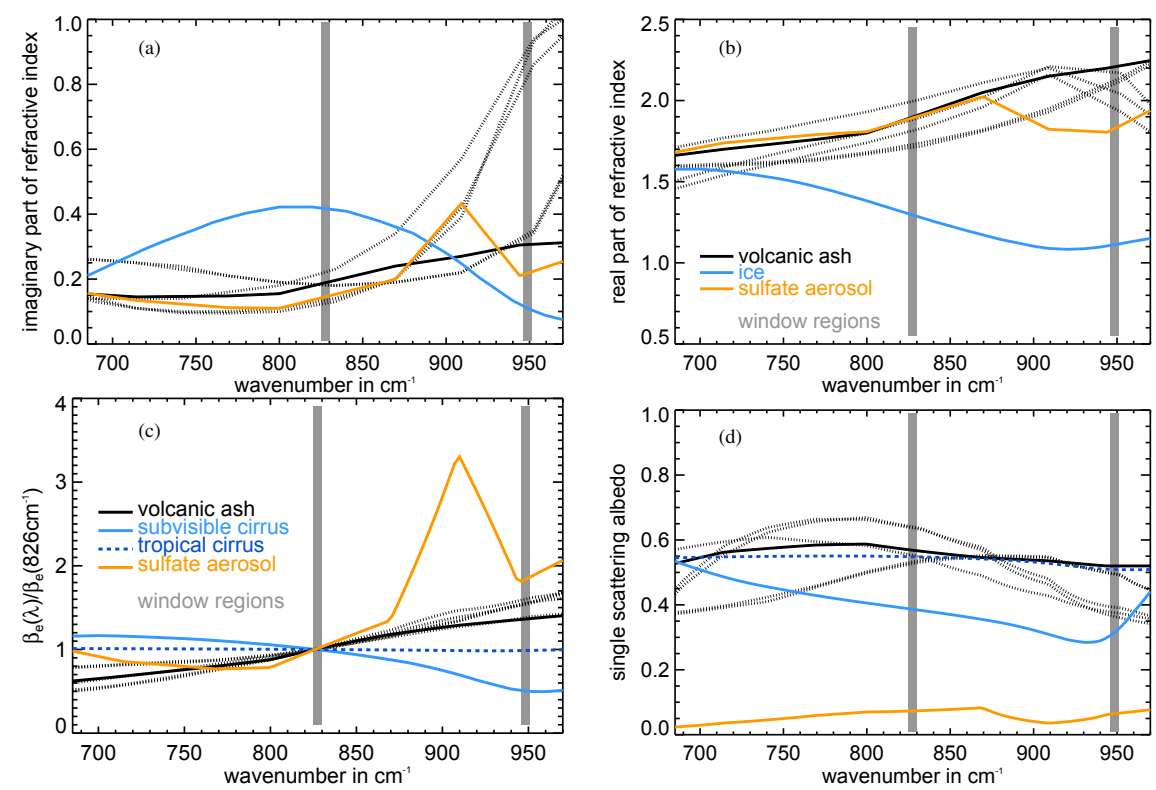

Figure 1. (a), (b) Complex refractive index spectra for volcanic ash (black solid line, Volz, 1973), volcanic ash compounds (black dotted lines for andesite, basalt, basaltic glass, and obsidian, Pollack et al., 1973), ice and sulfate aerosol in MIPAS band A. (c) Extinction coefficient and (d) single-scattering albedo spectra for volcanic ash, volcanic ash compounds, ice and sulfate aerosol. The corresponding particle size distributions are presented in Table 1 . The extinction coefficient is normalised to 1 at $826 \mathrm{~cm}^{-1}$. The grey regions denote atmospheric windows used for volcanic ash detection.

Table 2. Median radius for mono-modal log-normal size distributions shown in Fig. 2 and corresponding effective radius and scattering radius at $826 \mathrm{~cm}^{-1}$. The width is set to 1.6 .

\begin{tabular}{lcc}
\hline$\mu(\mu \mathrm{m})$ & $r_{\text {sca }}(\mu \mathrm{m})$ & $r_{\text {eff }}(\mu \mathrm{m})$ \\
\hline 0.3 & 1.2 & 0.5 \\
0.6 & 2.0 & 1.0 \\
1.15 & 2.9 & 2.0 \\
1.75 & 3.6 & 3.0 \\
2.9 & 4.9 & 5.0 \\
\hline
\end{tabular}

cirrus cloud, and stratospheric volcanically enhanced sulfate aerosol. For volcanic ash and sulfate aerosol there is an increase of the extinction coefficient from $826 \mathrm{~cm}^{-1}$ to $950 \mathrm{~cm}^{-1}$. The magnitude of the increase depends on the respective refractive index. In contrast, for small ice particles (SVC) there is a decrease, and for large ice particles (tropical cirrus) the extinction coefficient remains constant.

Regarding the single-scattering albedo, the spectral slope shows a decrease similar to small ice particles for three volcanic ash refractive indices and for the other three volcanic ash refractive indices it is very similar to large ice particles (tropical cirrus). The rather high single-scattering albedo of about $55 \%$ means that both the volcanic ash and the large ice particles (tropical cirrus) are good scatterers in the MIPAS band A range. Hence, the differences in MIPAS spectra caused by ice and volcanic ash are mainly due to opposite spectral slopes of the extinction coefficient. For sulfate aerosol the single-scattering albedo is smaller than $10 \%$. Therefore, we expect a weaker radiance increase relative to clear air for sulfate aerosol than for ice and volcanic ash in the MIPAS spectra.

The differences in extinction coefficient and singlescattering albedo for small and large ice particles reveal that the optical properties are strongly size dependent. The size dependency of ash particles and the variation range due to the refractive index is shown in Fig. 2. The median radii $(\mu)$ of the corresponding particle size distributions are given in Table 2 together with the scattering radii $\left(r_{\text {sca }}\right)$ that are weighted by the Mie scattering efficiency $\left(Q_{\text {sca }}\right)$ and the effective radii $\left(r_{\text {eff }}\right)$ that solely depend on the particle size distribution. Because volcanic ash size distributions have widths ranging from 1.1 to 2.2 (Farlow et al., 1981; Pueschel et al., 1994) we chose a constant width of 1.6 , which is in the middle. Figure 2 shows that with increasing particle size the increase of the extinction coefficient from 825 to $950 \mathrm{~cm}^{-1}$ becomes smaller and disappears for a scattering radius of $4.9 \mu \mathrm{m}$. Also, the variation range due to the refractive index becomes smaller with increasing particle size. For the size distributions with a scattering radius larger than $2.9 \mu \mathrm{m}$ the differences due to the particle size are larger than the differences due to the refractive index. Only for the two smallest scattering radii the refractive index variation range is significantly larger than the differences due to particle size. However, the size distributions with the smallest scattering radii show the strongest spectral slopes, but also have the smallest singlescattering albedos. Hence, from very small ash particle sizes 

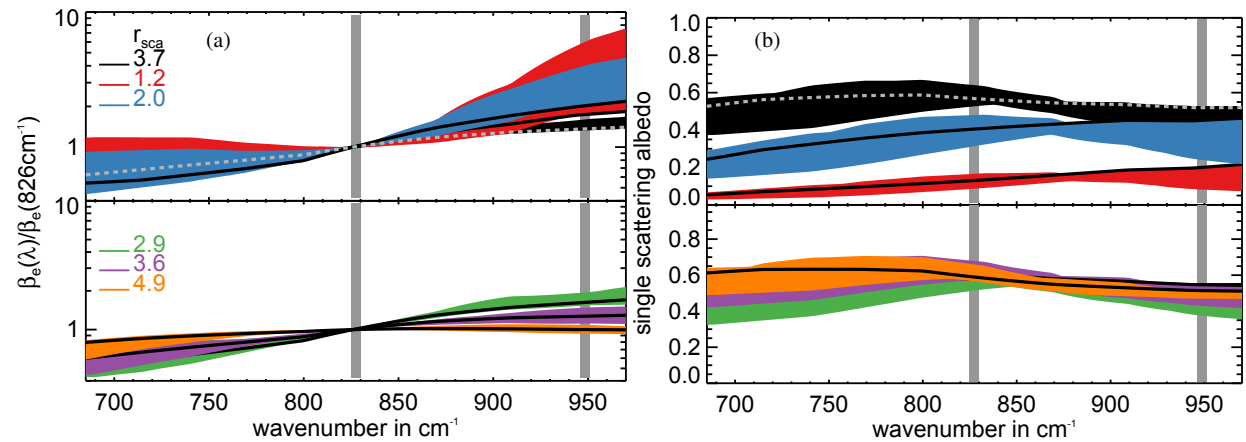

Figure 2. (a) Extinction coefficient and (b) single-scattering albedo spectra for volcanic ash particle size distributions with scattering radii ranging from 1.2 to $4.9 \mu \mathrm{m}$. The corresponding median radii and effective radii are given in Table 2 . The extinction coefficient spectra are normalised at $826 \mathrm{~cm}^{-1}$. The coloured areas denote the variation range due to different refractive index data sets for each size distribution. The black lines denote the Volz (1973) refractive index. The black area and the grey dashed line are calculated for the volcanic ash measurements reported by Schumann et al. (2011) with $r_{\mathrm{sca}}=3.7 \mu \mathrm{m}$.
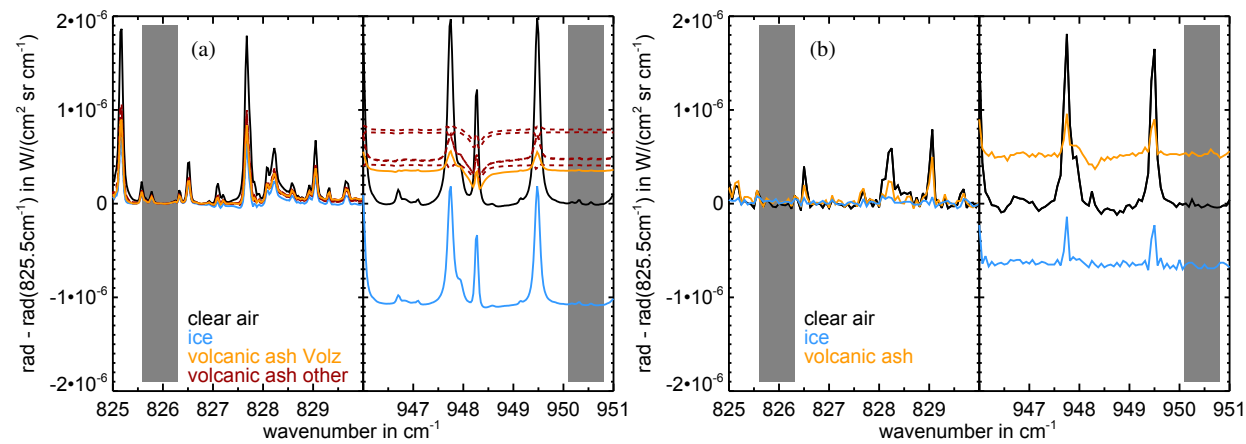

Figure 3. Simulated spectra and MIPAS measurements. (a) Pencil beam simulations for clear air, small ice particles (SVC), and small ash particles $\left(r_{\text {eff }}=1 \mu \mathrm{m}\right)$ at $10.0 \mathrm{~km}$ tangent altitude in mid-latitude atmospheric conditions. (b) MIPAS measurements (orbit 48509, profiles 89, 18, 65) for clear air, ice, and 6-day-old volcanic ash from Puyehue-Cordón Caulle eruption at tangent altitudes between 10 and 11 km. The spectra are levelled by subtracting the radiance at $826 \mathrm{~cm}^{-1}$.

we expect only a weak impact on the MIPAS spectra, and ash particle size distributions with scattering radii larger than or equal to $4.9 \mu \mathrm{m}$ will not be distinguishable from ice clouds for MIPAS band A spectra.

Although the measured ash particle size distribution in Table 1 has an effective radius of $0.8 \mu \mathrm{m}$, which is due to the strong first mode, its extinction coefficient spectrum is closer to the spectrum with an effective radius of $3.0 \mu \mathrm{m}$ in Fig. 2 . This is because both size distributions have similar scattering radii $(3.6$ and $3.7 \mu \mathrm{m})$. The spectral gradient of the extinction coefficient for particles with radii around $1 \mu \mathrm{m}$ in the midinfrared is rather dependent on the scattering radius than on the effective radius.

For both windows, at 825 and $950^{-1}$, we simulated the radiances for all volcanic ash types and compare them with a clear air and an ice cloud simulation in Fig. 3a. The spectra were simulated for a tangent altitude of $10 \mathrm{~km}$, neglecting the MIPAS field of view. These pencil beam simulations were made for the full-resolution mode of MIPAS assuming the mid-latitude atmosphere from Remedios et al. (2007). The homogeneous cloud layer was placed at 10 to $10.5 \mathrm{~km}$ altitude. For volcanic ash, the particle size distribution with the steepest extinction coefficient slope between both windows for the Volz (1973) refractive indices (i.e. effective radius of $1 \mu \mathrm{m})$ was taken, and for the ice cloud, the most contrasting particle size distribution of the SVC was taken. The trace gases contributing to the radiance signal between 825 and $830 \mathrm{~cm}^{-1}$ are $\mathrm{CO}_{2}, \mathrm{HNO}_{3}, \mathrm{H}_{2} \mathrm{O}, \mathrm{NO}_{2}, \mathrm{O}_{3}, \mathrm{ClONO}_{2}$, CFC$11, \mathrm{CFC}-22$, and $\mathrm{N}_{2} \mathrm{O}_{5}$ and between 946 and $951 \mathrm{~cm}^{-1}$ the contributing trace gases are $\mathrm{CO}_{2}, \mathrm{HNO}_{3}, \mathrm{H}_{2} \mathrm{O}, \mathrm{NO}_{2}, \mathrm{~N}_{2} \mathrm{O}$, $\mathrm{O}_{3}, \mathrm{~N}_{2} \mathrm{O}_{5}$, and $\mathrm{SF}_{6}$. The radiance at $826 \mathrm{~cm}^{-1}$ is subtracted from the spectra to facilitate the comparison of the different spectral gradients.

The differences in the extinction coefficient spectra for volcanic ash and the ice cloud directly transferred into the simulated spectra. When focusing on the spectral regions with the least trace gas contributions that are highlighted in grey, it is clearly visible that all volcanic ash types lead to a significant increase in radiance at $950^{-1}$ and the ice cloud leads to a decrease in radiance at $950^{-1}$ compared to clear 
Table 3. Ice: number concentration $n$ in $\mathrm{cm}^{-3}$ for different median radii $\mu$ in $\mu \mathrm{m}$ and extinction coefficients $\beta_{\mathrm{e}}$ in $\mathrm{km}^{-1}$. Realistic number concentrations in the order of magnitude that were reported by Krämer et al. (2009) and Tian et al. (2010) are underlined.

\begin{tabular}{|c|c|c|c|c|c|c|c|c|c|}
\hline \multirow[b]{2}{*}{$\mu$} & \multicolumn{2}{|l|}{$\beta_{\mathrm{e}}$} & \multirow[t]{2}{*}{$1 \times 10^{-3}$} & \multirow[t]{2}{*}{$5 \times 10^{-3}$} & \multirow[t]{2}{*}{$1 \times 10^{-2}$} & \multirow[t]{2}{*}{$5 \times 10^{-2}$} & \multirow[t]{2}{*}{$1 \times 10^{-1}$} & \multirow[t]{2}{*}{$5 \times 10^{-1}$} & \multirow[t]{2}{*}{1} \\
\hline & $r_{\mathrm{sca}}$ & $r_{\text {eff }}$ & & & & & & & \\
\hline 0.3 & 1.0 & 0.5 & $2.5 \times 10^{1}$ & $1.3 \times 10^{2}$ & $2.5 \times 10^{2}$ & $1.3 \times 10^{3}$ & $2.5 \times 10^{3}$ & $1.3 \times 10^{4}$ & $2.5 \times 10^{4}$ \\
\hline 0.6 & 1.6 & 1.0 & 3.1 & $1.5 \times 10^{1}$ & $3.1 \times 10^{1}$ & $1.5 \times 10^{2}$ & $3.1 \times 10^{2}$ & $1.5 \times 10^{3}$ & $3.1 \times 10^{3}$ \\
\hline 0.8 & 1.9 & 1.4 & $\overline{1.3}$ & 6.4 & $\overline{1.3 \times 10^{1}}$ & $6.4 \times 10^{1}$ & $1.3 \times 10^{2}$ & $6.4 \times 10^{2}$ & $1.3 \times 10^{3}$ \\
\hline 1.5 & 2.8 & 2.6 & $\overline{1.9} \times 10^{-1}$ & $\overline{9.4} \times 10^{-1}$ & 1.9 & 9.4 & $1.9 \times 10^{1}$ & $9.4 \times 10^{1}$ & $1.9 \times 10^{2}$ \\
\hline 3 & 4.7 & 5.2 & $2.5 \times 10^{-2}$ & $\overline{1.2 \times 10^{-1}}$ & $\overline{2.5} \times 10^{-1}$ & $\overline{1.2}$ & $\underline{2.5}$ & $\overline{1.2 \times 10^{1}}$ & $2.5 \times 10^{1}$ \\
\hline 6 & 9.4 & 10.4 & $\overline{3.8 \times 10^{-3}}$ & $\overline{1.9 \times 10^{-2}}$ & $\overline{3.8 \times 10^{-2}}$ & $\overline{1.9} \times 10^{-1}$ & $\overline{3.8} \times 10^{-1}$ & 1.9 & 3.8 \\
\hline 12 & 19.7 & 20.9 & $\overline{7.2 \times 10^{-4}}$ & $3.6 \times 10^{-3}$ & $\overline{7.2 \times 10^{-3}}$ & $\overline{3.6 \times 10^{-2}}$ & $\overline{7.2 \times 10^{-2}}$ & $\overline{3.6} \times 10^{-1}$ & $\overline{7.2} \times 10^{-1}$ \\
\hline 24 & 40.5 & 41.7 & $\overline{1.7 \times 10^{-4}}$ & $\overline{8.4 \times 10^{-4}}$ & $\overline{1.7 \times 10^{-3}}$ & $8.4 \times 10^{-3}$ & $\overline{1.7 \times 10^{-2}}$ & $\overline{8.4 \times 10^{-2}}$ & $\overline{1.7 \times 10^{-1}}$ \\
\hline 48 & 82.7 & 83.4 & $4.2 \times 10^{-5}$ & $2.1 \times 10^{-4}$ & $\overline{4.2 \times 10^{-4}}$ & $2.1 \times 10^{-3}$ & $\overline{4.2 \times 10^{-3}}$ & $2.1 \times 10^{-2}$ & $4.2 \times 10^{-2}$ \\
\hline 96 & 166.3 & 166.7 & $1.1 \times 10^{-5}$ & $5.4 \times 10^{-5}$ & $1.1 \times 10^{-4}$ & $\overline{5.4 \times 10^{-4}}$ & $1.1 \times 10^{-3}$ & $5.4 \times 10^{-3}$ & $1.1 \times 10^{-2}$ \\
\hline
\end{tabular}

air. For this particular size distribution the Volz (1973) refractive indices caused the smallest radiance increase compared to the other refractive indices and hence represent the most conservative assumption.

The simulations in Fig. 3a prompted us to look for positive spectral gradients corresponding to volcanic ash in the MIPAS data after a known strong volcanic eruption. We chose the eruption of the Puyehue-Cordón Caulle in 2011 (see Sect. 3.2 for eruption description). Radiance observations obtained for profile 65 of MIPAS orbit 48509 (10 June 2011, $41.5^{\circ} \mathrm{S}, 101.0^{\circ} \mathrm{E}$ ), exhibit a strong positive slope as expected for volcanic ash. In the same orbit we found an example for clear air (profile $89,48.9^{\circ} \mathrm{S}, 79^{\circ} \mathrm{W}$ ) and an ice cloud (profile $18,44.9^{\circ} \mathrm{N}, 64^{\circ} \mathrm{W}$ ) at 10 to $11 \mathrm{~km}$. From the measured spectra the radiance at $826 \mathrm{~cm}^{-1}$ is subtracted and shown in Fig. 3b. Compared to the simulations in Fig. 3a, the measurements of clear air, ice and volcanic ash show the expected spectral signatures: similar radiances at 826 and $950 \mathrm{~cm}^{-1}$ for clear air, a smaller radiance at $950 \mathrm{~cm}^{-1}$ than at $826 \mathrm{~cm}^{-1}$ for ice, and a larger radiance at $950 \mathrm{~cm}^{-1}$ than at $826 \mathrm{~cm}^{-1}$ for volcanic ash.

It should be noted that the radiances at the line centres do not match, which is mainly due to a difference in water content of the simulated atmosphere and the real atmosphere (water lines are located at 825.2, 827.5, 947.5, and $\left.949.5 \mathrm{~cm}^{-1}\right)$. Yet, for particle detection the radiances between the gas lines in the grey-shaded areas and the spectral gradient are of major interest. The differences between volcanic ash simulations with and without water vapour are 2 and 5 percentage points at 825.5 and $950.5 \mathrm{~cm}^{-1}$, respectively. As the impact of water vapour on the ash cloud spectra is very small and nearly constant, it does not affect the spectral slope due to volcanic ash.

\subsection{Volcanic ash detection threshold derived from MIPAS observations}

On 4 June 2011, the initial explosive eruption of the Puyehue-Cordón Caulle volcano complex, located in the southern Andes of Chile, injected volcanic ash up to about 11-14 km altitude (Smithonian Global Volcanism Programme, 2013). The eruption plume was observed by several nadir sounders measuring at ultraviolet (NASA Earth Observatory, 2013; NASA OMI, 2013), visible (NASA MODIS, 2013) and infrared wavelengths (Klüser et al., 2013). The nadir sounders traced the circulation of the volcanic ash around the Southern Hemisphere for more than 10 days. In the following we focus on MIPAS measurements in the Southern Hemisphere after the Puyehue-Cordón Caulle eruption.

A comprehensive view on MIPAS band A radiance spectra for tangent altitudes between 7 and $24 \mathrm{~km}$ is given in Fig. 4. The spectra for clear air, ice and volcanic ash in Fig. $3 b$ were extracted from these profiles. The clear air profile, Fig. $4 \mathrm{a}$, is characterised by strong $\mathrm{CO}_{2}$ lines between 750 and $800 \mathrm{~cm}^{-1}$ at all altitudes, CFC-11 bands around $850 \mathrm{~cm}^{-1}$ and CFC-12 bands around $920 \mathrm{~cm}^{-1}$ in the troposphere, $\mathrm{HNO}_{3}$ bands between 860 and $910 \mathrm{~cm}^{-1}$, and narrow $\mathrm{CO}_{2}$ lines at wave numbers larger than $920 \mathrm{~cm}^{-1}$. Around $830 \mathrm{~cm}^{-1}$ there is a large window and between the $\mathrm{CO}_{2}$ lines around $950 \mathrm{~cm}^{-1}$ there are several narrow but very distinct windows, where no trace gas has line centres. Because these windows are not affected by strong trace gas signals, they are particularly suited to detect clouds and aerosol. In the case of clear air, very little radiation is observed in these windows at all altitudes. If clouds or aerosol are present, as in the measurements in Fig. $4 \mathrm{~b}$ and c, the radiance is enhanced all over the spectrum and particularly in these windows. In Fig. $4 \mathrm{~b}$ the radiance is enhanced below $12.5 \mathrm{~km}$ due to a cloud. Within the cloud the radiance decreases with increasing wave number. As argued in Sect. 3.1, this is characteristic 

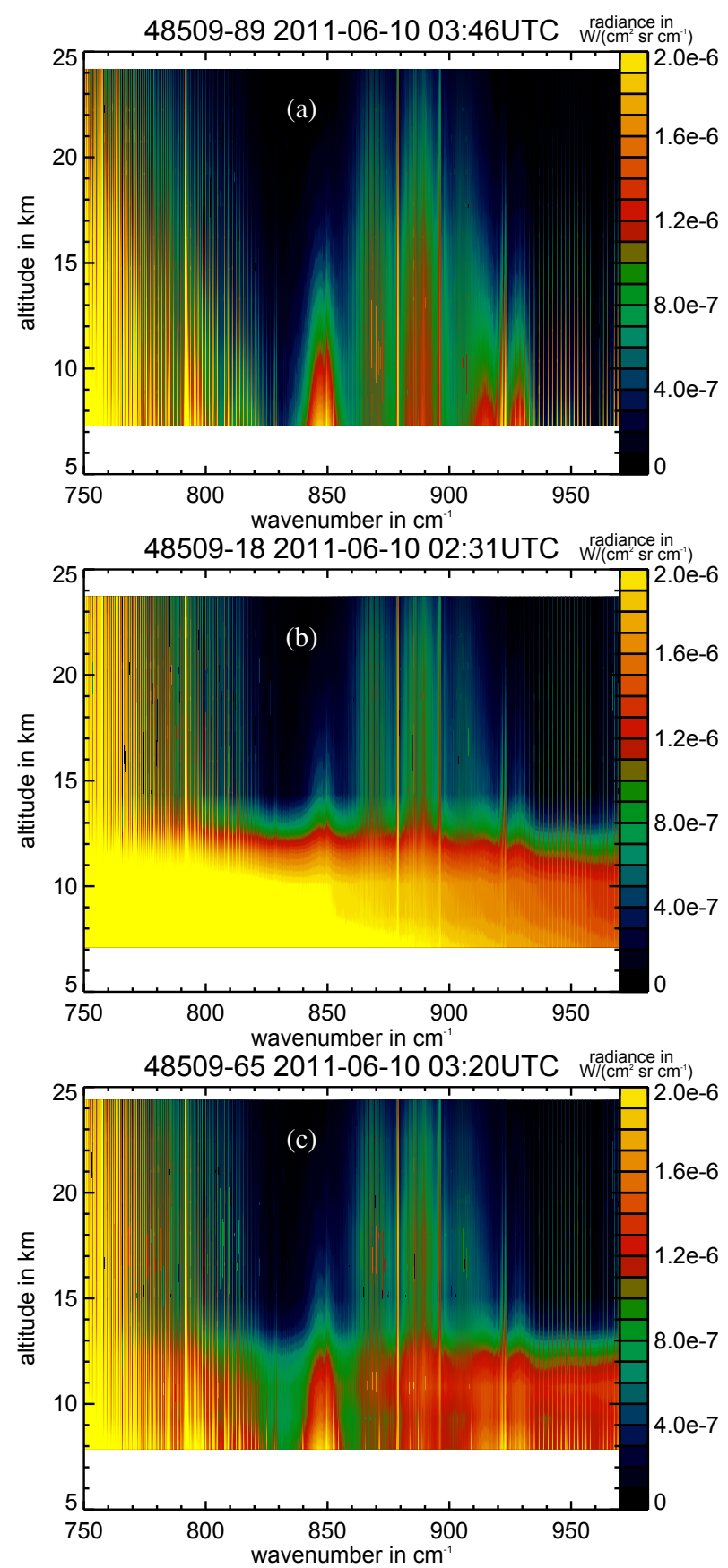

Figure 4. MIPAS radiances for three profiles of orbit 48509. (a) Clear air with low radiances in window regions around 830 and $950 \mathrm{~cm}^{-1}$. (b) Ice cloud below $13 \mathrm{~km}$. The radiances at $830 \mathrm{~cm}^{-1}$ are much larger than at $950 \mathrm{~cm}^{-1}$. (c) Volcanic ash layer below $13 \mathrm{~km}$. The radiances at $830 \mathrm{~cm}^{-1}$ are lower than at $950 \mathrm{~cm}^{-1}$.

for ice clouds or optically thick clouds. In contrast, the cloud in Fig. 4c causes increasing radiance with increasing wave number. Based on the theoretical analysis in Sect. 3.1, this is the expected radiance signal for volcanic ash.

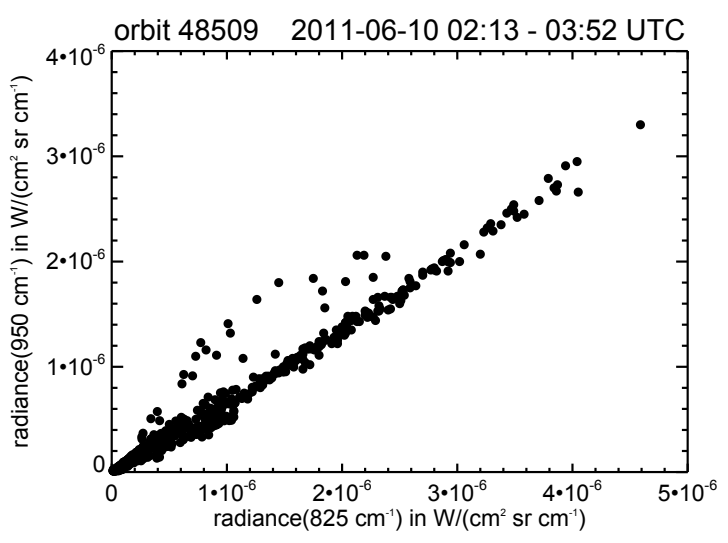

Figure 5. Mean radiances below $30 \mathrm{~km}$ tangent altitude for the $825 \mathrm{~cm}^{-1}$ window versus the $950 \mathrm{~cm}^{-1}$ window for MIPAS orbit 48509. The measurements form a narrow band with some outliers that are characteristic for volcanic ash. This orbit was measured six days after the Puyehue-Cordón Caulle eruption in Chile.

Aiming for a fast detection method that makes it possible to discriminate between ice and volcanic ash clouds and that is as insensitive as possible towards changes in trace gas concentrations, we chose two narrow spectral windows close to the 830 and $950 \mathrm{~cm}^{-1}$ windows in Fig. 4a so that gas line contributions to the radiance signal are negligible within these windows. One window is located at 825.6 to $826.3 \mathrm{~cm}^{-1}$ containing 10 spectral points and the other is located at 950.1 to $950.9 \mathrm{~cm}^{-1}$, also containing 10 spectral points. In Fig. 3 both regions are highlighted with grey bars. For these regions, we averaged the radiances and performed a correlation analysis. The results for all spectra measured below $30 \mathrm{~km}$ altitude of MIPAS orbit 48509, which contains the profiles in Fig. 4, is shown in Fig. 5. For clear air and ice cloud measurements the radiances cluster around a line. However, some measurements stand out and show significantly higher radiances at $950 \mathrm{~cm}^{-1}$. These measurements were made in regions where volcanic ash was present according to NASA Earth Observatory (2013).

To derive a threshold function that separates volcanic ash from clear air and ice cloud scenarios, we analysed all measurements below $30 \mathrm{~km}$ altitude in the Southern Hemisphere in 2011. Because the Puyehue-Cordón Caulle eruption started on 4 June 2011 and we found numerous cases with enhanced radiances at $950 \mathrm{~cm}^{-1}$ compared to $825 \mathrm{~cm}^{-1}$ until August, we grouped the data into three groups: January to May is the pre-eruption phase, June to August is the first post-eruption phase, and September to December is the second post-eruption phase. Figure 6 shows the occurrence frequency of the radiance combinations for the three phases. In the pre-eruption phase all observations cluster around a narrow line. In the first post-eruption phase a distinct second branch with higher radiances at $950 \mathrm{~cm}^{-1}$ shows up. These higher radiances at $950 \mathrm{~cm}^{-1}$ disappear in the second posteruption phase so that it is very similar to the pre-eruption 

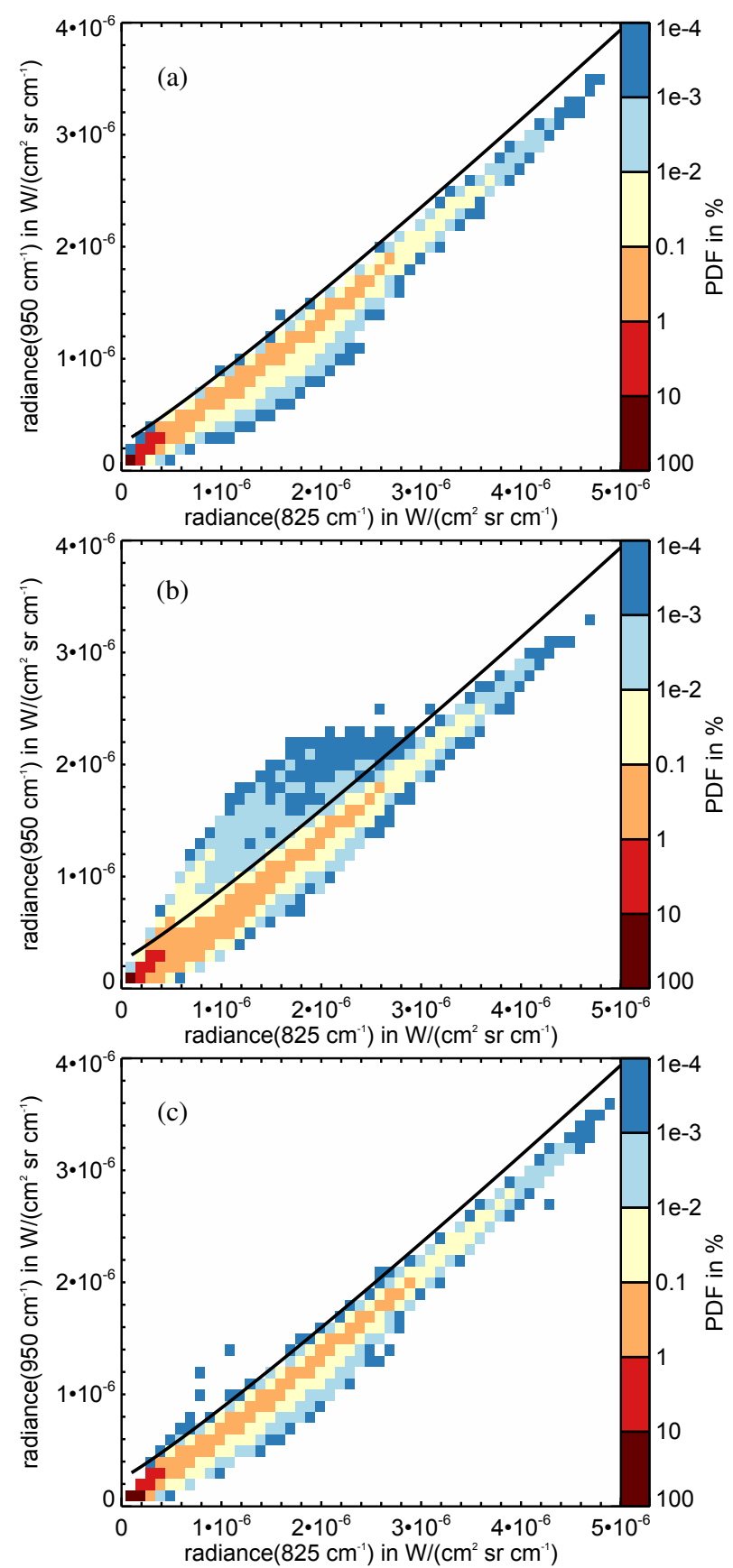

Figure 6. Frequency density of MIPAS radiances in the Southern Hemisphere below $30 \mathrm{~km}$ altitude. (a) Pre-eruption phase from January to May 2011. (b) Post-eruption phase from June to August 2011. The eruption of the Puyehue-Cordón Caulle started on 4 June 2011. (c) Post-eruption phase from September to December 2011. The black line is the ash detection threshold function.

phase. Assuming that the pre-eruption phase and the second post-eruption phase are mainly volcanically undisturbed situations, we fit an ash detection threshold function to the upper edge of the observations:

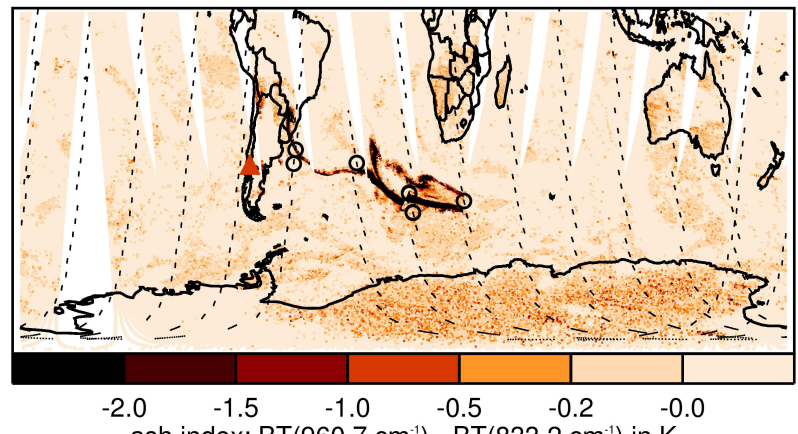

ash index: BT(960.7 $\left.\mathrm{cm}^{-1}\right)-\mathrm{BT}\left(833.2 \mathrm{~cm}^{-1}\right)$ in $\mathrm{K}$

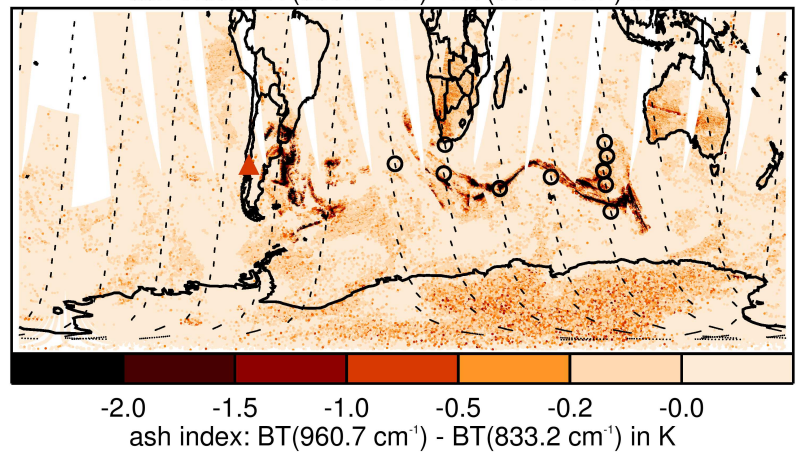

Figure 7. MIPAS and AIRS volcanic ash detections between 12:00 and 24:00 UTC on 7 and 9 June 2011. The AIRS ash index (brightness temperature $\left(960.7 \mathrm{~cm}^{-1}\right)$ - brightness temperature $\left.\left(833.2 \mathrm{~cm}^{-1}\right)\right)$ is colour coded. The black circles indicate the profiles where volcanic ash was detected by MIPAS. The PuyehueCordón Caulle is marked by the red triangle and the black dashes denote the MIPAS tangent points below $30 \mathrm{~km}$.

$$
\begin{aligned}
I\left(950 \mathrm{~cm}^{-1}\right) & \geq 2.5 \times I\left(825 \mathrm{~cm}^{-1}\right)^{1.1} \\
+ & 2.5 \times 10^{-7} \frac{\mathrm{W}}{\mathrm{cm}^{2} \mathrm{srcm}^{-1}},
\end{aligned}
$$

where $I$ is the radiance in $\mathrm{W}\left(\mathrm{m}^{2} \mathrm{srcm}^{-1}\right)^{-1}$ at the respective wave number, from the observations. To assure that the measurements with significantly higher radiances at $950 \mathrm{~cm}^{-1}$ are not due to polar stratospheric clouds (PSCs), which are present every polar night over Antarctica, we did the same analysis, but excluded all measurements south of $60^{\circ} \mathrm{S}$ (not shown). This did not change the results significantly. This threshold function provides a reliable ash detection method and makes it possible to analyse several years of MIPAS data very quickly.

We applied the ash detection threshold to MIPAS measurements after the Puyehue-Cordón Caulle eruption. In Fig. 7, the Puyehue-Cordón Caulle volcanic ash plume detected by MIPAS and AIRS between 12:00 and 24:00 UTC on 7 and 9 June 2011 are shown. On 7 June the AIRS data show the ash plume confined to a rather narrow filament extending from south Brazil over the south Atlantic to south of the southern tip of Africa. Two days later the ash plume 


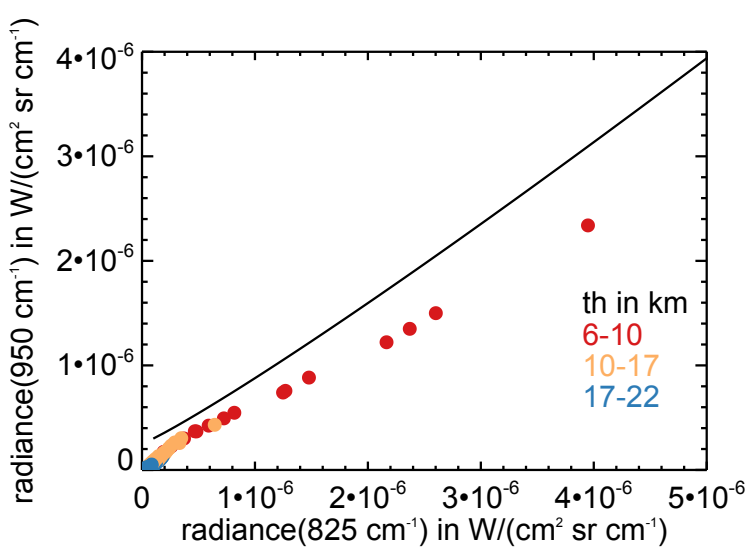

Figure 8. Simulation results for clear air at tangent heights (th) between 6 and $22 \mathrm{~km}$ in polar winter, polar summer and mid-latitude atmosphere and 10 and $22 \mathrm{~km}$ in equatorial atmosphere. The black line denotes the ash detection threshold as derived from measurements.

was transported further east and a wave-like filament extends from the south Atlantic to the south Pacific. Some fresher plumes are located over the Atlantic close to the South American coast. MIPAS detects the volcanic ash in the same regions as AIRS. Slight differences in location can be attributed to differences in measurement time (up to $12 \mathrm{~h}$ ), as the plume is moving very fast. Furthermore, we also processed the MIPAS data from 2006 to 2012 and detected volcanic ash after all major eruptions, such as Kasatochi, Chaiten and Sarychev (Griessbach et al., 2012).

\section{Scattering simulation study}

\subsection{Simulation setup}

To support and characterise the ash detection threshold function derived from measurement data, we performed radiative transfer simulations with JURASSIC to model the radiances as measured by the MIPAS instrument. To show that the scenarios exceeding the ash detection threshold in Fig. $6 \mathrm{~b}$ are of volcanic origin, the simulations cover various clear air, ice cloud, volcanic ash and sulfate aerosol scenarios. Clear air simulations for different atmospheric conditions are performed first, to ascertain that clear air conditions cannot lead to the observed radiances. Since ice clouds are the major cloud type in the upper troposphere and lower stratosphere (UTLS), we simulated ice cloud scenarios next. Ash clouds are simulated to identify the scenarios that exceed the ash detection threshold derived from observations. Sulfate aerosol is also considered to account for the fact that volcanic eruptions generally emit $\mathrm{SO}_{2}$, which forms sulfate aerosol or leads to a sulfate coating on volcanic ash particles.
The general simulation setup is as follows: we simulated the radiances in the two windows between $825.6-826.3 \mathrm{~cm}^{-1}$ and $950.1-950.9 \mathrm{~cm}^{-1}$ using the same trace gases as in Sect. 3.1. To cover a wide range of atmospheric variability we used four different atmospheric profiles representing a wide range of atmospheric conditions: polar winter, polar summer, mid-latitude night and equatorial night taken from Remedios et al. (2007). From 2005 to 2012, the nominal MIPAS measurements were made down to $10 \mathrm{~km}$ in the tropics and $6 \mathrm{~km}$ in the mid-latitude and polar regions. Therefore we simulated the radiances at tangent altitudes ranging from 10 to $22 \mathrm{~km}$ in the tropics and 6-22 km at higher latitudes on a $1 \mathrm{~km}$ grid taking into account the MIPAS field of view as described in Sect. 2.2.

Ice clouds and volcanic aerosol can be very variable in their macro-physical and micro-physical properties. Regarding their shape, horizontal and vertical extent we chose a homogeneous cloud layer of $1 \mathrm{~km}$ thickness with sharp cloud edges, realised by a transition layer of $10 \mathrm{~m}$, in which the particle number concentration decreased to zero. A cloud layer was placed at four different altitudes, $6-7 \mathrm{~km}, 9-10 \mathrm{~km}$, $13-14 \mathrm{~km}$, and $17-18 \mathrm{~km}$, in each atmosphere, except for the tropical atmosphere, where only clouds above $10 \mathrm{~km}$ are considered. For simplicity we assumed the idealised case of one cloud per scenario and neglected layered cloud structures. Of course, real clouds are much more complex. They occur at different altitudes, have a large range of possible vertical extent, have complex 3-D structures, and are inhomogeneous in their micro-physical properties. However, this simulation study is set up to demonstrate that volcanic ash leads to unique signals, which makes it possible to identify volcanic ash in infrared limb measurements.

Wen and Rose (1994) found a stronger sensitivity on the size distribution than the refractive index for volcanic ash. Therefore, the micro-physical properties are restricted to one refractive index data set per particle type and the particle size distribution is varied. As atmospheric particles are not monodisperse, we assumed log-normal size distributions for the ice, ash and sulfate aerosol clouds. Log-normal size distributions are well suited for ice (e.g. Tian et al., 2010), volcanic ash (e.g. Farlow et al., 1981) and sulfate aerosol clouds (e.g. Deshler et al., 1992, 1993). Although volcanic aerosol is often best described by multi-modal size distributions (e.g. Pueschel et al., 1994), we restricted the simulations to a single mode with a width of 1.6 for simplicity. The median radius and the number concentration were varied to cover a wide range for each particle type. The ranges are given in each section, respectively and the most likely combinations of particle size and concentration according to measurements are highlighted. Altogether we simulated 60848 spectra for this study. 

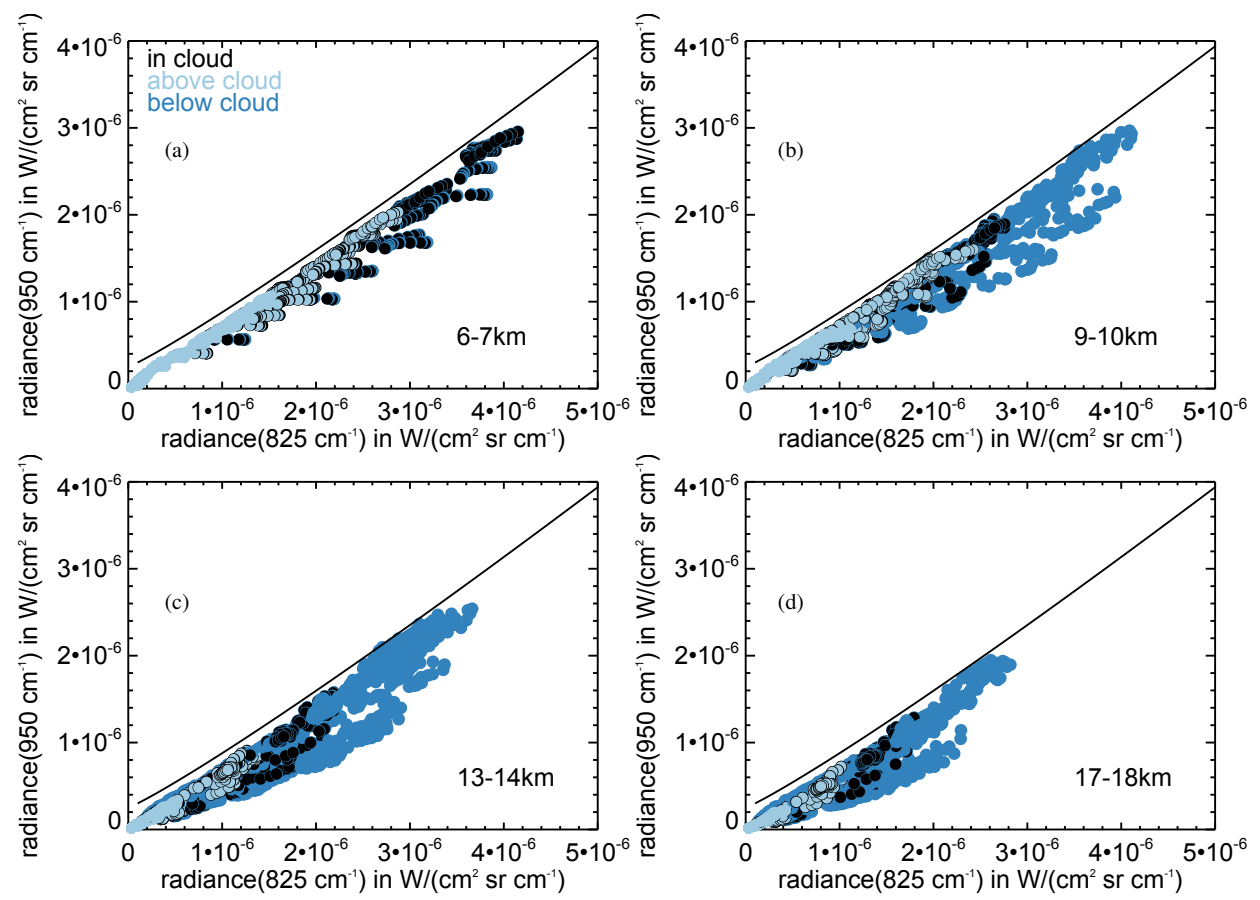

Figure 9. Simulated radiances for ice clouds. (a) Ice cloud at 6-7 km altitude in polar winter, polar summer and mid-latitude atmosphere. (b) Ice cloud at 9-10 km altitude in polar winter, polar summer and mid-latitude atmosphere. (c) Ice cloud at 13-14 km altitude in polar winter, mid-latitude and equatorial atmosphere. (d) Ice cloud at $17-18 \mathrm{~km}$ altitude in polar winter and equatorial atmosphere. The black line is the ash detection threshold. The tangent altitudes from cloud bottom to $6 \mathrm{~km}$ are coloured in blue, the tangent altitudes within the cloud are coloured in black, and tangent altitudes above the ice cloud are coloured in light blue.

\subsection{Clear air simulations}

The simulated radiances for clear air conditions are shown in Fig. 8 in the same type of scatter plot as in Figs. 5 and 6 for the measurements. The ash detection threshold from Eq. (2) is indicated by the black line. For clear air conditions the radiances are below $1 \times 10^{-6} \mathrm{~W}\left(\mathrm{~m}^{-2} \mathrm{srcm}^{-1}\right)^{-1}$ in the polar winter atmosphere or at higher altitudes. At lower altitudes the radiances increase. All clear air scenarios are well below the ash detection threshold. From this we conclude that the measurements exceeding the ash detection threshold in Fig. 6 are not clear air conditions, but rather caused by atmospheric particles.

\subsection{Ice cloud simulations}

For the ice cloud simulations, we used the infrared complex refractive indices by Warren and Brandt (2008). The ice cloud simulation setup requires some restrictions to represent realistic scenarios. The ice cloud at $18 \mathrm{~km}$ altitude was simulated only in the polar winter and the equatorial atmosphere, because in polar summer and at mid-latitudes, ice clouds cannot be expected at this altitude. For the same reason the ice cloud at $14 \mathrm{~km}$ altitude was not simulated for the polar summer atmosphere.
The simulations were performed for cloud extinction coefficients ranging from $1 \times 10^{-3}$ to $5 \times 10^{-1} \mathrm{~km}^{-1}$ in steps of half an order of magnitude. For each extinction coefficient we generated 10 particle size distributions with median radii ranging from 0.3 to $96 \mu \mathrm{m}$ according to in situ measured particle sizes reported by Krämer et al. (2009) and Tian et al. (2010). In Table 3 the extinction coefficients, median radii and the corresponding particle concentrations are given. According to the measurements reported by Krämer et al. (2009), not all number concentrations necessary to reach the extinction coefficient are realistic. Hence, the most realistic scenarios with concentrations ranging from about $1 \times 10^{-3}$ to $100 \mathrm{~cm}^{-3}$ are highlighted in Table 3 .

The simulation results for the ice clouds are shown in Fig. 9 for the four cloud altitudes. The tangent altitudes are grouped into three groups: above the cloud, in the cloud and below the cloud. For all simulated scenarios shown in Fig. 9, the ash detection threshold is not exceeded. This leads to the conclusion that the MIPAS observations exceeding the ash detection threshold in Fig. 6b are not caused by ice clouds.

Regarding MIPAS measurements from 2002 to 2004, where the nominal measurements were made down to $6 \mathrm{~km}$ also in the tropics, we simulated tangent altitudes down to $6 \mathrm{~km}$ and clouds below $10 \mathrm{~km}$ also in the equatorial scenario. The atmosphere there is very dense and water vapour concentration is very high. Even the clear air simulations were 
Table 4. Ash: number concentration $n$ in $\mathrm{cm}^{-3}$ for every median radius $\mu$ in $\mu \mathrm{m}$ and extinction coefficient $\beta_{\mathrm{e}}$ in $\mathrm{km}^{-1}$. Most likely combinations of number concentrations and particle sizes according to Mossop (1964), Farlow et al. (1981) and Schumann et al. (2011) are underlined. The number scenarios that exceed the ash detection threshold are emphasised in bold font.

\begin{tabular}{|c|c|c|c|c|c|c|c|c|}
\hline$\mu$ & $\begin{array}{c}\beta_{\mathrm{e}} \\
r_{\text {rsca }}\end{array}$ & $r_{\text {eff }}$ & $1 \times 10^{-3}$ & $5 \times 10^{-3}$ & $1 \times 10^{-2}$ & $5 \times 10^{-2}$ & $1 \times 10^{-1}$ & $5 \times 10^{-1}$ \\
\hline 0.1 & 0.4 & 0.2 & $5.6 \times 10^{2}$ & $2.8 \times 10^{3}$ & $5.6 \times 10^{3}$ & $2.8 \times 10^{4}$ & $5.6 \times 10^{4}$ & $2.8 \times 10^{5}$ \\
\hline 0.3 & 1.0 & 0.5 & $1.4 \times 10^{1}$ & $\underline{6.8 \times 10^{1}}$ & $1.4 \times 10^{2}$ & $6.8 \times 10^{2}$ & $1.4 \times 10^{3}$ & $6.8 \times 10^{3}$ \\
\hline 0.6 & 1.5 & 1.0 & $\overline{7.7 \times 10^{-1}}$ & $\overline{3.9}$ & 7.7 & $3.9 \times 10^{1}$ & $7.7 \times 10^{1}$ & $3.9 \times 10^{2}$ \\
\hline 0.8 & 1.8 & 1.4 & $\overline{2.5 \times 10^{-1}}$ & $\overline{1.2}$ & $\overline{2.5}$ & $1.2 \times 10^{1}$ & $2.5 \times 10^{1}$ & $1.2 \times 10^{2}$ \\
\hline 1.0 & 2.1 & 1.7 & $\overline{1.1 \times 10^{-1}}$ & $\overline{5.6} \times 10^{-1}$ & $\overline{1.1}$ & 5.6 & $1.1 \times 10^{1}$ & $5.6 \times 10^{1}$ \\
\hline 1.25 & 2.3 & 2.2 & $\overline{5.6 \times 10^{-2}}$ & $2.8 \times 10^{-1}$ & $\overline{5.6} \times 10^{-1}$ & $\underline{\overline{2.8}}$ & 5.6 & $2.8 \times 10^{1}$ \\
\hline 1.5 & 2.6 & 2.6 & $3.4 \times 10^{-2}$ & $1.7 \times 10^{-1}$ & $3.4 \times 10^{-1}$ & $\overline{1.7}$ & 3.4 & $1.7 \times 10^{1}$ \\
\hline 2.0 & 3.2 & 3.5 & $\overline{1.7 \times 10^{-2}}$ & $8.5 \times 10^{-2}$ & $\overline{1.7 \times 10^{-1}}$ & $\overline{8.5} \times 10^{-1}$ & $\overline{1.7}$ & 8.5 \\
\hline 3.0 & 4.7 & 5.2 & $7.7 \times 10^{-3}$ & $\overline{3.8 \times 10^{-2}}$ & $\overline{7.6 \times 10^{-2}}$ & $\overline{3.8 \times 10^{-1}}$ & $\overline{7.6} \times 10^{-1}$ & $\overline{3.8}$ \\
\hline 5.0 & 8.2 & 8.7 & $3.0 \times 10^{-3}$ & $1.5 \times 10^{-2}$ & $3.0 \times 10^{-2}$ & $1.5 \times 10^{-1}$ & $3.0 \times 10^{-1}$ & $\underline{1.5}$ \\
\hline
\end{tabular}

already optically thick and clear air as well as cloud simulations were saturated and both reached the same radiances (not shown). In the case of high-altitude ice clouds $(18,14$, and $10 \mathrm{~km}$ ), we found that for lower tangent altitudes the radiances were smaller than for the clear air scenario and that the ash detection threshold was exceeded in a few cases for tangent altitudes well below the cloud layers at altitudes up to $8 \mathrm{~km}$. In these particular cases, the extinction coefficient ranges from 0.01 to $0.1 \mathrm{~km}^{-1}$ and the median radii are always smaller than or equal to $6 \mu \mathrm{m}$. These median radii are very small and can only be expected for sub-visible cirrus clouds (Iwasaki et al., 2007; Lawson et al., 2008; Davis et al., 2010; Frey et al., 2011). Hence, for the analysis of MIPAS measurements from 2002 to 2004, care must be taken in the tropics. For MIPAS data evaluation since 2005, this finding is irrelevant, because in the tropics tangent altitudes are above $10 \mathrm{~km}$.

\subsection{Volcanic ash simulations}

For the ash cloud simulations we used the infrared complex refractive indices by Volz (1973) that are found in the HITRAN Shettle compilation (Rothman et al., 2009) for volcanic dust. In Table 4 the median radii, extinction coefficients and corresponding number concentrations are given. As described in Sect. 3.1, in the infrared, the spectral gradient of the extinction coefficient vanishes for larger volcanic ash particles. For this reason we restricted the simulations to particle size distributions with median radii up to $5 \mu \mathrm{m}$. In situ measurements of small volcanic ash particles in the middle troposphere and UTLS found particle concentrations ranging from $7 \times 10^{-4}$ to $40 \mathrm{~cm}^{-3}$ (Mossop, 1964; Farlow et al., 1981; Schumann et al., 2011). This most likely range is highlighted in Table 4.
The results of the ash simulations are shown in Fig. 10 for the four ash layers. The three groups of tangent altitudes, above the ash cloud, within the ash cloud and below the ash cloud, are colour coded. The difference to the ice cloud simulations is clearly visible. A substantial fraction of the simulated scenarios exceeds the ash detection threshold. The strongest effect is observed for the two highest ash clouds. The shapes in Fig. 10c and d for the 14 and $18 \mathrm{~km}$ ash layer very much resemble the shape of the MIPAS measurements in Fig. 6b. However, the simulated detached group with radiances above $3 \times 10^{-6} \mathrm{~W}\left(\mathrm{~m}^{2} \mathrm{srcm}^{-1}\right)^{-1}$ at $825 \mathrm{~cm}^{-1}$ is not found in the measurements. The reason for this difference is that the volcanic ash was injected into the Southern Hemisphere mid-latitude and polar regions in June and the simulations exceeding the ash detection threshold in the detached group are solely tropical and polar summer scenarios. The scenarios exceeding the ash detection threshold are emphasised in bold font in Table 4. From the simulations we derived a detectable extinction coefficient range of $5 \times 10^{-3}$ to $1 \times 10^{-1} \mathrm{~km}^{-1}$ for this method. The simulations also showed that only particle size distributions with effective radii smaller than $3.5 \mu \mathrm{m}$ can be discriminated from ice clouds. Hence, the ash detection threshold is exceeded only by small ash particles. For larger ash particle sizes or very low or high extinction coefficients ash clouds cannot be discriminated from ice clouds. For particle size distributions with effective radii of $0.2 \mu \mathrm{m}$ and smaller, very high particle concentrations (more than $2000 \mathrm{~cm}^{-3}$ ) are required to reach detectable extinctions. Although there is no physical reason for a lower detection limit, we think that it is unlikely to detect volcanic ash particle size distributions with effective radii smaller than $0.2 \mu \mathrm{m}$ with this method, because such high particle concentrations have not been reported in measurements. 

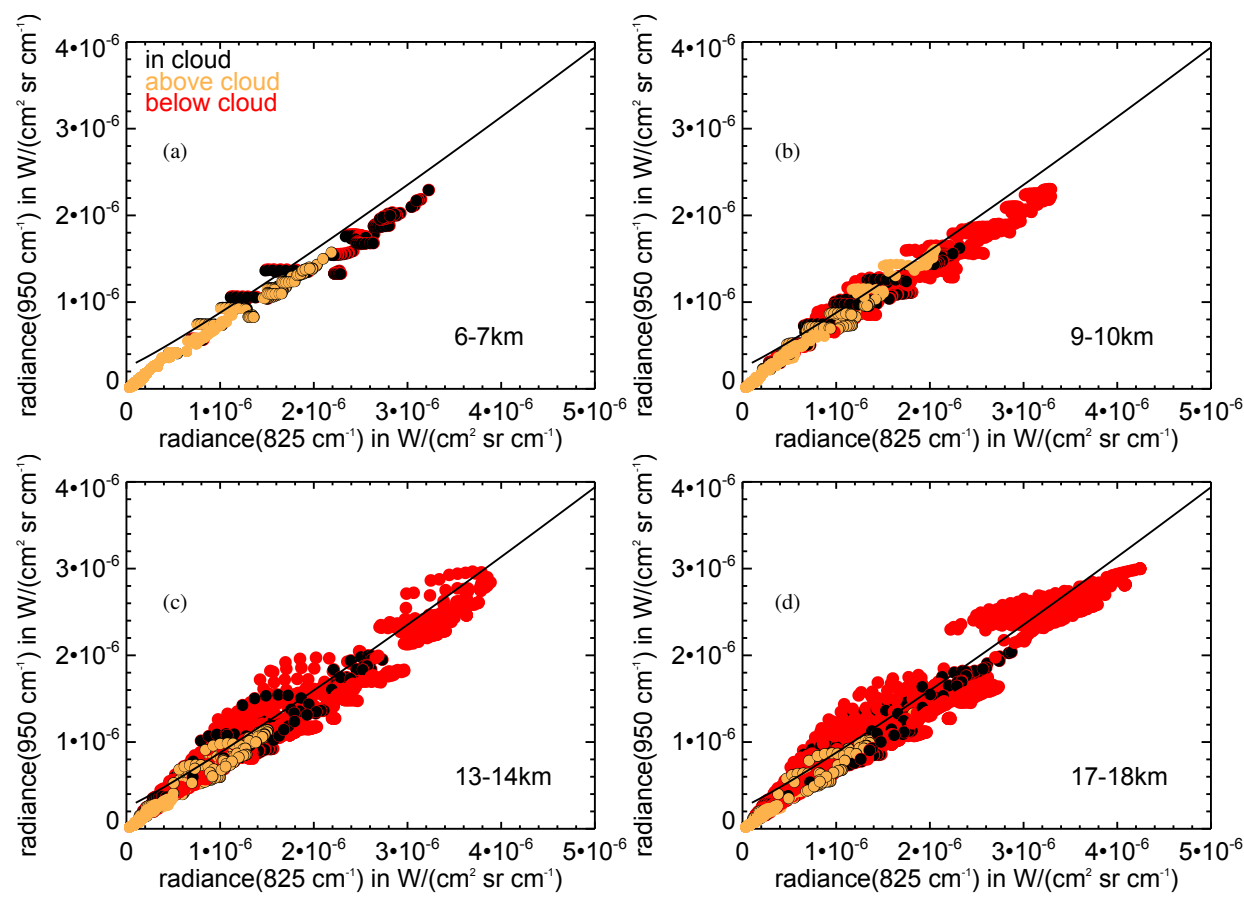

Figure 10. Simulated radiances for ash clouds. (a) Ash layer at 6-7 km altitude in polar winter, polar summer and mid-latitude atmosphere. (b) Ash layer at $9-10 \mathrm{~km}$ altitude in polar winter, polar summer and mid-latitude atmosphere. (c) Ash layer at 13-14 km altitude in polar winter, polar summer, mid-latitude and equatorial atmosphere. (d) Ash layer at $17-18 \mathrm{~km}$ altitude in polar winter, polar summer, mid-latitude, and equatorial atmosphere. The black line is the ash detection threshold. The tangent altitudes from the ash layer bottom to $6 \mathrm{~km}$ are coloured in red, the tangent altitudes within the ash layer are coloured in black, and tangent altitudes above the ash layer are coloured in orange.
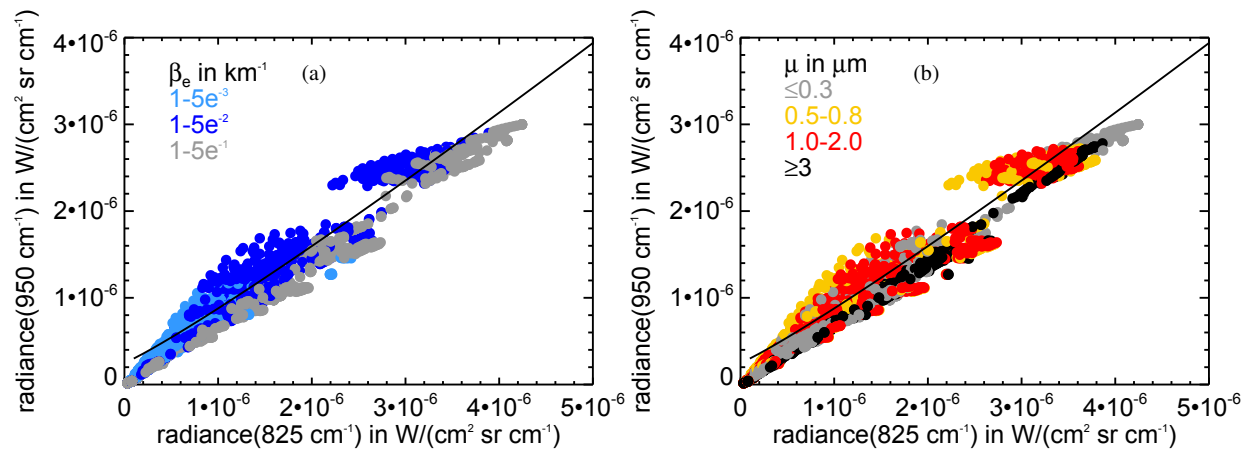

Figure 11. (a) Extinction coefficient and (b) radius dependencies for volcanic ash clouds at $18 \mathrm{~km}$ altitude. The black line is the ash detection threshold.

In Fig. 11 the simulation results for the ash cloud at $18 \mathrm{~km}$ altitude are shown again, but with extinction coefficient and median radius colour coded. The simulations for large extinction coefficients and large particles follow a line right below the ash detection threshold. This group below the ash detection threshold is the limit for optically thick scenarios and blackbodies in the extreme. For the simulations that exceed the ash detection threshold, there is an ash detection optimum for extinction coefficients of the order of magnitude of $1 \times 10^{-2} \mathrm{~km}^{-1}$. For these scenarios the distance to the ash detection threshold is at its maximum. For the ash detection optimum not only the extinction coefficient is relevant. Even more important is the particle size. The ash detection optimum is reached for particle size distributions with median radii between 0.5 and $2.0 \mu \mathrm{m}\left(r_{\text {eff }}=0.9-1.4 \mu \mathrm{m}\right)$. Smaller particles still cause radiance signals that exceed the ash detection threshold, but their radiances are closer to the ash detection threshold than the radiances for the optimum-sized particles.

For the volcanic ash simulations, the ash detection threshold is not only exceeded at tangent altitudes within the ash layer, but also at tangent altitudes below and slightly above 

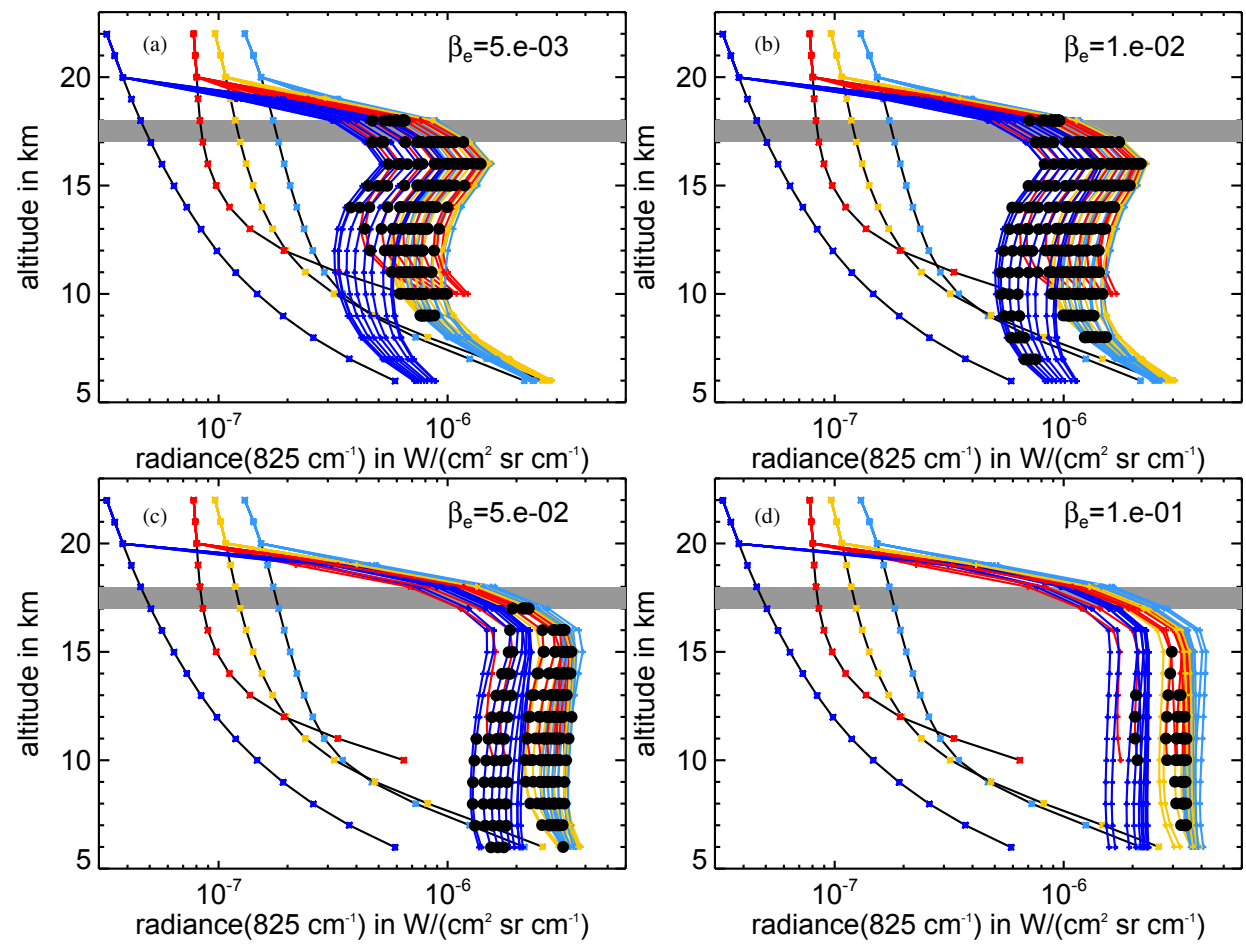

Figure 12. Simulated radiances for ash layers between 17 and $18 \mathrm{~km}$ with extinction coefficients of $5 \times 10^{-3} \mathrm{~km}^{-1}, 1 \times 10^{-2} \mathrm{~km}^{-1}$, $5 \times 10^{-2} \mathrm{~km}^{-1}$ and $1 \times 10^{-1} \mathrm{~km}^{-1}$. The black dots mark the tangent altitudes where the ash detection threshold is exceeded. The black profiles are the clear air simulations for polar winter (blue), polar summer (light blue), mid-latitude (yellow) and equatorial (red) atmosphere.

(up to $10 \mathrm{~m}$ ) the ash layer. The simulated profiles for the ash layer between 17 and $18 \mathrm{~km}$ altitude are shown in Fig. 12 for the four extinction coefficients that allow for ash detection. Although the profiles show enhanced radiances $1 \mathrm{~km}$ above the ash layer, due to the MIPAS field of view, we only find ash detections at ash layer top altitude (and $10 \mathrm{~m}$ above). From this we conclude that MIPAS volcanic ash detections are always less than $1 \mathrm{~km}$ above the actual ash layer top altitude. In Fig. 12, it also becomes apparent that the ash detection method clearly identifies volcanic ash contaminated profiles, but tends to underestimate the ash layer top altitude, especially for extinction coefficients larger than $5 \times 10^{-2} \mathrm{~km}^{-1}$.

Regarding the ash layer bottom altitude, the shape of the vertical radiance profiles in Fig. 12 indicates that for optically thick clouds $\left(\beta_{\mathrm{e}} \geq 5 \times 10^{-2} \mathrm{~km}^{-1}\right)$ no bottom altitude can be estimated. For optically thin ash layers there is a local radiance maximum $1 \mathrm{~km}$ below the ash layer. This maximum is likely useful to determine the ash layer bottom altitude.

\subsection{Sulfate aerosol simulations}

A further challenge for volcanic ash detection is that usually volcanic eruptions also emit substantial amounts of sulfur dioxide, which forms sulfate aerosol or leads to a liquid sulfate coating on ash particles typically on a timescale of a few days after the eruption (Farlow et al., 1981). Infrared limb measurements are highly sensitive to atmospheric particles and can be severely affected by enhanced stratospheric sulfate aerosol as happened after the Mt. Pinatubo eruption for measurements of the ISAMS (Lambert et al., 1993) and CLAES (Massie et al., 1996) instruments. Wen and Rose (1994) applied windows similar to ours for volcanic ash retrieval from infrared nadir measurements and found that sulfate aerosol with more than $50 \%$ sulfuric acid is indistinguishable from solid volcanic aerosol. To investigate whether sulfate aerosol also affects the volcanic ash detection method for infrared limb measurements we simulated sulfate aerosol scenarios with a $75 \%$ sulfuric acid solution that is most realistic for the UTLS region. The infrared complex refractive indices of sulfate aerosol used for the simulation are from the Hummel et al. (1988) data compiled in the HITRAN Shettle data file (Rothman et al., 2009).

The extinction coefficients, particle size distribution median radii and the corresponding particle concentrations used for the simulations are given in Table 5. The most likely range of sulfate aerosol particle sizes and concentrations covering undisturbed and volcanically enhanced conditions is underlined according to in situ (Mossop, 1964; Farlow et al., 1981; Deshler et al., 1992, 1993) and remote sensing measurements (Stothers, 2001; Bauman et al., 2003). 
Table 5. Sulfate aerosol: number concentration $n$ in $\mathrm{cm}^{-3}$ for every median radius $\mu$ in $\mu \mathrm{m}$ and extinction coefficient $\beta_{\mathrm{e}}$ in $\mathrm{km}{ }^{-1}$. The most likely combinations of number concentration and particle size according to measurements (Mossop, 1964; Farlow et al., 1981; Deshler et al., 1992, 1993; Stothers, 2001; Bauman et al., 2003) are underlined. The scenarios exceeding the ash detection threshold are emphasised in bold font.

\begin{tabular}{ccrlllll}
\hline & \multicolumn{1}{c}{$\beta_{\mathrm{e}}$} & & $1 \times 10^{-4}$ & $5 \times 10^{-4}$ & $1 \times 10^{-3}$ & $5 \times 10^{-3}$ & $1 \times 10^{-2}$ \\
$\mu$ & $r_{\text {sca }}$ & $r_{\text {eff }}$ & & & & & \\
\hline 0.01 & 0.04 & 0.02 & $5.9 \times 10^{4}$ & $3.0 \times 10^{5}$ & $5.9 \times 10^{5}$ & $\mathbf{3 . 0} \times \mathbf{1 0}^{\mathbf{6}}$ & $\mathbf{5 . 9} \times \mathbf{1 0}^{\mathbf{6}}$ \\
0.05 & 0.21 & 0.09 & $4.7 \times 10^{2}$ & $2.4 \times 10^{3}$ & $4.7 \times 10^{3}$ & $\mathbf{2 . 4} \times \mathbf{1 0}^{\mathbf{4}}$ & $\mathbf{4 . 7} \times \mathbf{1 0}^{\mathbf{4}}$ \\
0.1 & 0.4 & 0.2 & $\underline{5.8 \times 10^{1}}$ & $2.9 \times 10^{2}$ & $5.8 \times 10^{2}$ & $\mathbf{2 . 9} \times \mathbf{1 0}^{\mathbf{3}}$ & $\mathbf{5 . 8} \times \mathbf{1 0}^{\mathbf{3}}$ \\
0.2 & 0.7 & 0.4 & $\underline{6.6}$ & $\underline{3.3 \times 10^{1}}$ & $6.6 \times 10^{1}$ & $\mathbf{3 . 3} \times \mathbf{1 0}^{\mathbf{2}}$ & $\mathbf{6 . 6} \times \mathbf{1 0}^{\mathbf{2}}$ \\
0.3 & 0.9 & 0.5 & $\underline{1.6}$ & $\underline{8.2}$ & $\underline{1.6 \times 10^{1}}$ & $\mathbf{8 . 2} \times \mathbf{1 0}^{\mathbf{1}}$ & $\mathbf{1 . 6} \times \mathbf{1 0}^{\mathbf{2}}$ \\
0.5 & 1.3 & 0.9 & $\underline{2.4} \times 10^{-1}$ & $\underline{1.2}$ & $\underline{2.4}$ & $\mathbf{1 . 2} \times \mathbf{1 0}^{\mathbf{1}}$ & $\mathbf{2 . 4} \times \mathbf{1 0}^{\mathbf{1}}$ \\
0.6 & 1.4 & 1.0 & $\underline{1.1 \times 10^{-1}}$ & $\underline{5.7 \times 10^{-1}}$ & $\underline{1.1}$ & $\mathbf{5 . 7}$ & $\mathbf{1 . 1} \times \mathbf{1 0}^{\mathbf{1}}$ \\
0.8 & 1.7 & 1.4 & $3.7 \times 10^{-2}$ & $1.8 \times 10^{-1}$ & $3.7 \times 10^{-1}$ & $\mathbf{1 . 8}$ & $\mathbf{3 . 7}$ \\
1.0 & 2.0 & 1.7 & $1.6 \times 10^{-2}$ & $8.1 \times 10^{-2}$ & $1.6 \times 10^{-1}$ & $\mathbf{8 . 1} \times \mathbf{1 0}^{-\mathbf{1}}$ & $\mathbf{1 . 6}$ \\
1.25 & 2.4 & 2.2 & $7.6 \times 10^{-3}$ & $3.8 \times 10^{-2}$ & $7.6 \times 10^{-2}$ & $\mathbf{3 . 8} \times \mathbf{1 0}^{-\mathbf{1}}$ & $\mathbf{7 . 5} \times \mathbf{1 0}^{-\mathbf{1}}$ \\
1.5 & 2.7 & 2.6 & $4.3 \times 10^{-3}$ & $2.1 \times 10^{-2}$ & $4.3 \times 10^{-2}$ & $2.1 \times 10^{-1}$ & $\mathbf{4 . 3} \times \mathbf{1 0}^{-1}$ \\
\hline
\end{tabular}

During volcanically quiescent periods, the concentration of sulfuric acid particles with radii $\geq 0.15 \mu \mathrm{m}$ is low at about $0.01 \mathrm{~cm}^{-3}$ (Pruppacher and Klett, 2010). With altitude, the concentration rises about one order of magnitude and reaches 0.05 to $0.2 \mathrm{~cm}^{-3}$ in the Junge layer between about 15 to $25 \mathrm{~km}$ altitude (Pruppacher and Klett, 2010, and references therein). The infrared extinction coefficient for these undisturbed conditions is of the order of $1 \times 10^{-5} \mathrm{~km}^{-1}$. After the eruption of Mt. Pinatubo in 1991, which was the strongest volcanic eruption in the last century, enhanced particle concentrations of up to $50 \mathrm{~cm}^{-3}$ for particles larger than $0.15 \mu \mathrm{m}$ were reported (Fig. 1 in Deshler et al., 1992). Deshler et al. (1993) present a time series of measured number size distributions with particle concentrations of about 3 to $50 \mathrm{~cm}^{-3}$ for median radii between 0.04 and $0.3 \mu \mathrm{m}$ and up to $2 \mathrm{~cm}^{-3}$ for larger median radii $\leq 0.6 \mu \mathrm{m}$. The extinction coefficient measured at $12.82 \mu \mathrm{m}$ by CLAES a couple of months after the eruption was up to $1 \times 10^{-3} \mathrm{~km}^{-1}$. Remote sensing measurements of stratospheric aerosol presented by Stothers (2001) for major eruptions in the twentieth century and by Bauman et al. (2003) for the period since 1985 reported effective radii between 0.2 and $0.6 \mu \mathrm{m}$. This is somewhat smaller than the sizes derived from in situ measurements. In Table 5 the largest possible range is highlighted.

Pueschel et al. (1994) reported a single aerosol particle mode around $0.1 \mu \mathrm{m}$ in the UTLS region for background conditions. After volcanic eruptions, they found a second, larger mode around $0.4 \mu \mathrm{m}$ due to enhanced sulfate aerosol and a third mode around $0.8 \mu \mathrm{m}$ containing volcanic ash particles. Within a few days after volcanic eruptions gaseous $\mathrm{SO}_{2}$ condenses at the volcanic ash particle's surface and forms a sulfate coating (Mossop, 1964; Farlow et al., 1981; Pueschel et al., 1994). This coating changes the complex refractive index of volcanic aerosol. To account for sulfate coating on ash particles in this study, the parameter range of the sulfate aerosol is extended to larger median radii, particle concentrations and extinction coefficients, respectively. We consider these simulations for larger sulfate aerosol particles and realistic concentrations as proxies for sulfate-coated ash particles.

The simulation results for sulfate aerosol are shown in Fig. 13 in the same style as the results for the ice and ash clouds. The simulations form a narrow line around the ash detection threshold and some scenarios exceed the ash detection threshold. The scenarios that exceed the threshold are marked in Table 5 in bold font. They are not within the range of measured sulfate aerosol particle concentrations and sizes, not even for the largest volcanic eruption of the last 100 years, Mt. Pinatubo. However, they might be caused by sulfate-coated ash particles.

The volcanic eruption with the largest $\mathrm{SO}_{2}$ emission during the MIPAS measurement period from 2002 to 2012 was the eruption of the Eritrean Nabro volcano on 13 June 2011. It injected about $1.5 \mathrm{Tg} \mathrm{SO}_{2}$ (Clarisse et al., 2012) into the atmosphere, which is about one order of magnitude less than the $20 \mathrm{Tg} \mathrm{SO}$ from Mt. Pinatubo (Bluth et al., 1992). The $\mathrm{SO}_{2}$ was oxidised to sulfate aerosol and formed a stratospheric aerosol layer in the Northern Hemisphere (Bourassa et al., 2012; Sawamura et al., 2012). Due to the much smaller amount of $\mathrm{SO}_{2}$, for this event it is unlikely that the presented volcanic ash detection method would wrongly identify the sulfate aerosol layer as volcanic ash. The analysis of the MIPAS data confirms this. In the MIPAS profiles we clearly identified stratospheric aerosol a few days after the eruption and an aerosol layer covering the Northern Hemisphere about 2 months after the eruption for several months. However, the new ash detection method did not classify this 

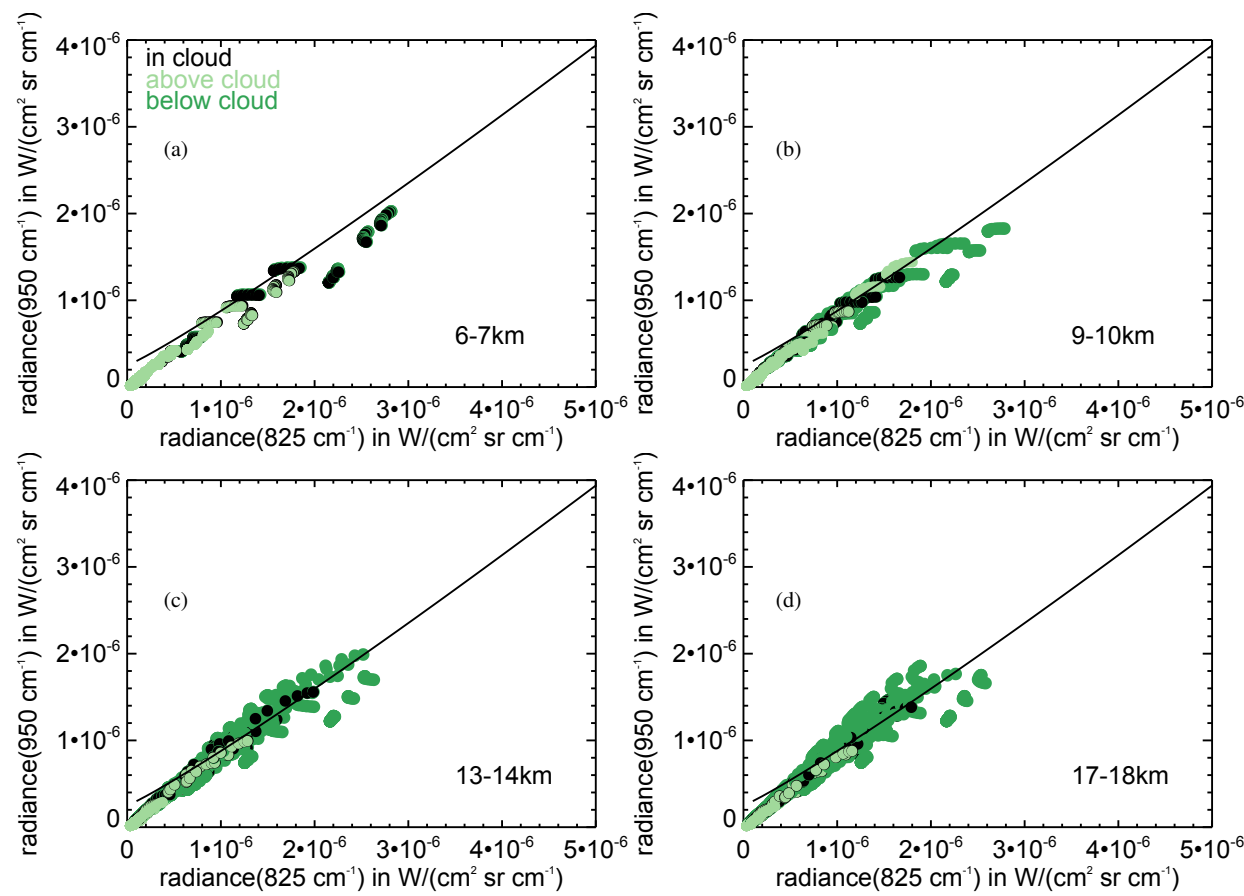

Figure 13. Simulated radiances for sulfate aerosol layers. (a) Sulfate aerosol layer at 6-7 km altitude in polar winter, polar summer and mid-latitude atmosphere. (b) Sulfate aerosol layer at 9-10 km altitude in polar winter, polar summer and mid-latitude atmosphere. (c) Sulfate aerosol layer at $13-14 \mathrm{~km}$ altitude in polar winter, polar summer, mid-latitude and equatorial atmosphere. (d) Sulfate aerosol layer at $17-$ $18 \mathrm{~km}$ altitude in polar winter, polar summer, mid-latitude and equatorial atmosphere. The black line is the ash detection threshold. The tangent altitudes from the sulfate layer bottom to $6 \mathrm{~km}$ are coloured in green, the tangent altitudes within the sulfate layer are coloured black, and tangent altitudes above the sulfate layer are coloured light green.

enhanced sulfate aerosol layer as volcanic ash, giving confidence in our ash detection methodology.

Assuming the theoretical case of completely coated ash particles that are masked by sulfuric acid, and assuming these particles have either an effective size of at least $1.4 \mu \mathrm{m}$ or number concentrations larger than $5 \mathrm{~cm}^{-3}$, these particles could be detected by the ash detection method. Because these particles are a mixture of sulfuric acid solution and mainly volcanic ash, the detection as ash particles is correct. However, measurements by Pueschel et al. (1994) show that ash particles are not homogeneously coated. For this reason the mixed particle's refractive index might be somewhere between volcanic ash and sulfate aerosol. To this effect, the sulfate aerosol simulations with larger median radii and large particle concentrations are the upper limit to which the refractive index can be changed.

After all, for infrared limb sounding measurements volcanic ash discrimination from sulfate aerosol is mainly a question of number size distribution. Our simulations showed that pure sulfate aerosol particles are too small or too few to be detected with the ash detection method. Yet, within a certain particle size and number concentration range, completely sulfate-coated ash particles are also detectable with the ash detection method.

\section{Discussion}

\subsection{Volcanic ash detections in relation to cloud index}

The CI is a standard method for cloud and aerosol detection using MIPAS measurements. MIPAS CI values lower than 1.8 indicate clouds and CI values larger than 4 to 5 indicate clear air (Spang et al., 2004). CI values in between relate to optically very thin clouds or clouds that expand over only a small part of the MIPAS field of view. For more specialised purposes Spang and Remedios (2003, for CRISTA) and Höpfner et al. (2009) use a cloud detection threshold of 4.5 for polar stratospheric clouds and, depending on altitude, season and latitude, Sembhi et al. (2012) suggest a CI up to 6 for cloud and aerosol detection.

To investigate the possible CI range of volcanic ash detections we calculated the CIs of the MIPAS volcanic ash detections for the Puyehue-Cordón Caulle eruption shown in Fig. 6b. The CIs range from 4.2 to 1.0 and have a median of 2.8. Compared to the thresholds used in the other studies, the Puyehue ash detections range from clear air to very thick clouds and are on average located between the two thresholds. Hence, the Puyehue ash is detectable with the CI. Since the ash detection method underestimates the ash layer top 
altitude in several cases, the CI can be used to determine the ash cloud top altitude.

\subsection{Other particle types}

From simulations of extinction coefficient and singlescattering albedo spectra for other aerosol types, we found that certain particle sizes of carbonaceous material and mineral dust have a spectral behaviour very similar to volcanic ash. From this, we deduce that the method presented above is also capable of detecting mineral dust or smoke from wildfires. For the MIPAS measurements, we found that the threshold was also exceeded by some aerosol injected by the Black Saturday bush fire in February 2009 in Australia, some other wild fires, as well as mineral dust outbreaks in central Asia. Therefore, the MIPAS measurements offer the opportunity to study aerosol from other sources as well.

\subsection{Volcanic ash detection method for limb measurements in relation to nadir measurements}

For infrared nadir measurements, Prata (1989a, b) showed that it is possible to discriminate between volcanic ash, sulfate aerosol, or quartz containing material and ice or water clouds by using brightness temperature differences (BTDs) between two windows at 10.8 and $11.9 \mu \mathrm{m}$ (926 and $840 \mathrm{~cm}^{-1}$ ). Both windows are located in atmospheric window regions, where the optical properties of ice and volcanic ash are different. Likewise we use similar windows at 950 and $825 \mathrm{~cm}^{-1}$ (10.5 and $12.1 \mu \mathrm{m}$, respectively) for the ash detection method presented here. The similarities between our new method for volcanic ash detection from infrared limb measurements and existing nadir techniques motivated us to briefly compare the capabilities of both methods. We found that the detectable particle size range is the same for infrared nadir and limb measurements. Yet, due to the two different viewing geometries, we found that limb measurements with their longer viewing paths through the atmosphere can detect considerably smaller particle concentrations than the nadir measurements.

From theoretical considerations and simulations, Prata (1989b, see Table 2 and Fig. 1) derived that in the infrared particle sizes up to $2-3 \mu \mathrm{m}$ can be detected. Wen and Rose (1994) found that negative BTDs, required for volcanic ash detection, are possible for particle sizes up to $5 \mu \mathrm{m}$ and derived a sensitivity range of 0.8 to $4.3 \mu \mathrm{m}$ for the effective radius of a mono-disperse size distribution. These results are in excellent agreement with our findings that ash particles with effective radii between 0.5 and $3.5 \mu \mathrm{m}$ (median radii: 0.3 to $2.0 \mu \mathrm{m}$ ) are detectable with infrared limb measurements. The small differences are due to differences in the assumed particle size distributions (mono-disperse, poly-disperse, different distribution widths).
For infrared nadir measurements, Prata (1989b) found that volcanic ash clouds cannot be discriminated from sulfate aerosol clouds or sulfate-coated ash clouds by utilising the BTD method. Barton et al. (1992) demonstrated a case in which this method detects a volcanic sulfate aerosol cloud. Wen and Rose (1994) examined whether volcanic ash and sulfate aerosol can be distinguished from each other and concluded from their simulations that sulfate aerosol with sulfuric acid concentrations larger than $50 \%$ cannot be distinguished from volcanic ash aerosol. In contrast to Wen and Rose (1994), we could show that for infrared limb measurements volcanic ash can be discriminated from sulfate aerosol consisting of $75 \%$ sulfuric acid solution. However, our method is also sensitive to sulfate-coated ash particles, provided that they are larger or more numerous than the sulfate aerosol particles measured so far.

The range of optical depth for the volcanic ash particle size retrieval introduced by Wen and Rose (1994) is from 0.1 to 1.25 . More recent volcanic aerosol retrieval range down to optical depths of 0.02 (Clarisse et al., 2010; Gangale et al., 2010). Assuming an aerosol layer with a vertical extent of $1 \mathrm{~km}$, the extinction coefficients given in Table 4 can directly be compared to the optical depths. For an ash layer of $1 \mathrm{~km}$ thickness, limb measurements can classify ash layers with lower particle concentrations (optical depth of $5 \times 10^{-3}$ ) than nadir measurements due to longer path lengths through the layer. This sensitivity to lower particle concentrations makes it possible to trace ash particles for up to 3 months as shown for the Puyehue-Cordón Caulle eruption.

The cloud top height of the volcanic ash layers can be determined for opaque cloud parts by comparing brightness temperatures from infrared nadir measurements with atmospheric temperature profiles (Prata and Grant, 2001). For thin cloud parts and clouds near the tropopause, this method leads to errors (Prata and Grant, 2001). In contrast, our detection method for limb radiance profiles in conjunction with the CI makes it possible to determine the cloud top altitude irrespective of thick or thin ash layers. Additionally, limb measurements may allow the layer bottom altitude to be estimated for optically thin ash layers. Altitude-resolved information on volcanic plumes derived by utilising this fast detection method could also be of use to e.g. the Volcanic Ash Advisory Centres.

\section{Summary and conclusions}

We have demonstrated that volcanic ash can be detected from MIPAS band A infrared limb measurements and determined the detectable particle size and extinction coefficient range. Starting with the complex refractive indices for volcanic ash and ice particles, we derived the extinction coefficient and single-scattering albedo spectra. The spectral gradient of the extinction coefficient spectrum of ice is in opposition to the 
gradient of the volcanic ash extinction coefficient spectrum. With radiative transfer simulations for clear air, ice clouds and volcanic ash, we showed that the opposing gradients directly transfer into the infrared limb spectra and create characteristic signals for ice and volcanic ash.

We exploited the high spectral resolution of MIPAS and identified two micro-windows between trace gas lines with low trace gas contributions at 825.6 to $826.3 \mathrm{~cm}^{-1}$ and 950.1 to $950.9 \mathrm{~cm}^{-1}$. These windows can be used to discriminate volcanic ash and ice clouds, because of characteristic spectral gradients produced by the different particles. For the gradient between both windows, we derived an ash detection threshold function to distinguish between volcanic ash and ice clouds from MIPAS measurements in the Southern Hemisphere in 2011. The ash detection threshold was chosen to identify all measurements between January and May 2011 as of non-volcanic origin. After the eruption of the PuyehueCordón Caulle on 4 June 2011 we found several measurements exceeding this threshold until August 2011. Even after August 2011 we found sporadic measurements exceeding this threshold. This method is both reliable and fast, because it applies the averages of narrow spectral windows and a computationally inexpensive threshold function.

In a comprehensive simulation study, we calculated the radiances in both windows for ice clouds, volcanic ash and sulfate aerosol. The particle sizes and concentrations were chosen to cover the realistic range observed in in situ particle measurements. The simulations confirm that the ash detection threshold cannot be exceeded by ice clouds, but can be exceeded by volcanic ash. From the simulations we found that volcanic ash particles with effective radii smaller than $3.5 \mu \mathrm{m}$ are detectable with infrared limb measurements, which is in agreement with the detectable particle size range for infrared nadir measurements. Larger volcanic ash particles can be detected with infrared limb measurements by applying the CI method, but cannot be discriminated from ice clouds. From the simulations, we derived the detectable extinction coefficient range of $5 \times 10^{-3}$ to $1 \times 10^{-1} \mathrm{~km}^{-1}$. In the case of an ash layer of $1 \mathrm{~km}$ vertical extent, the detectable extinction coefficient is about one order of magnitude smaller than for nadir measurements. We further found that for volcanic ash particles with effective radii smaller than $0.2 \mu \mathrm{m}$ the particle concentrations must be unrealistically high to be detectable. Hence, we conclude that these small ash particles are very unlikely to be detected with this method.

Because nadir volcanic ash detection methods are also sensitive to enhanced sulfate aerosol, we investigated the sensitivity of our method towards sulfate aerosol. Our simulations showed that background aerosol as well as volcanically enhanced sulfate aerosol, as measured after e.g. the Pinatubo eruption, can explicitly be discriminated from volcanic ash. MIPAS measurements of the sulfate aerosol layer after the Nabro eruption in 2011 also did not lead to ash detections with this method. However, sulfate-coated ash particles can be detected, provided they are large and numerous enough. From studies with other refractive indices as well as from MIPAS measurements we found that the ash detection method is also sensitive to mineral dust and carbonaceous material.

Owing to the fact that the ash detection methods for infrared limb and nadir measurements rely on the same optical properties, the detectable particle sizes are the same. The different measurement geometries, however, lead to a higher sensitivity towards smaller particle concentrations for the limb measurements. Hence, from infrared limb measurements, thinner ash clouds can be detected. Also, the limb measurements inherently provide altitude information in contrast to nadir measurements. Compared to measurements in the ultraviolet and visible spectral range, infrared limb emission measurements allow for measurements at night-time and hence provide a better global coverage. This volcanic ash detection method allows for fast analyses of infrared limb measurements and provides complementary information to already existing volcanic ash detection methods from other remote sensing instruments.

Acknowledgements. The MIPAS data were provided by the European Space Agency. We are grateful to Marc von Hobe and Rolf Müller for their continuous support, fruitful discussions and comments on the paper.

The service charges for this open access publication have been covered by a Research Centre of the Helmholtz Association.

Edited by: A. Lambert

\section{References}

Barton, I. J., Prata, A. J., Watterson, I. G., and Young, S. A.: Identification of the Mount Hudson volcanic cloud over SE Australia, Geophys. Res. Lett., 19, 1211-1214, doi:10.1029/92GL01122, 1992.

Bauman, J. J., Russell, P. B., Geller, M. A., and Hamill, P.: A stratospheric aerosol climatology from SAGE II and CLAES measurements: 1. Methodology, J. Geophys. Res., 108, 4382, doi:10.1029/2002JD002992, 2003.

Bluth, G., Doiron, S., Schnetzler, C., Krueger, A., and Walter, L.: Global tracking of the $\mathrm{SO}_{2}$ clouds from the June, 1991 Mount Pinatubo eruptions, Geophys. Res. Lett., 19, 151-154, doi:10.1029/91GL02792, 1992.

Bourassa, A. E., Robock, A., Randel, W. J., Deshler, T., Rieger, L. A., Lloyd, N. D., Llewellyn, E. J. T., and Degenstein, D. A.: Large Volcanic Aerosol Load in the Stratosphere Linked to Asian Monsoon Transport, Science, 337, 78-81, doi:10.1126/science.1219371, 2012.

Casadevall, T.: The 1989-1990 eruption of Redoubt volcano, Alaska - impacts on aircraft operations, J. Volc. Geotherm. Res., 62, 301-316, doi:10.1016/0377-0273(94)90038-8, 1994.

Clarisse, L., Hurtmans, D., Prata, A. J., Karagulian, F., Clerbaux, C., De Maziere, M., and Coheur, P.-F.: Retrieving radius, concentra- 
tion, optical depth, and mass of different types of aerosols from high-resolution infrared nadir spectra, Appl. Optics, 49, 37133722, 2010.

Clarisse, L., Hurtmans, D., Clerbaux, C., Hadji-Lazaro, J., Ngadi, Y., and Coheur, P.-F.: Retrieval of sulphur dioxide from the infrared atmospheric sounding interferometer (IASI), Atmos. Meas. Tech., 5, 581-594, doi:10.5194/amt-5-581-2012, 2012.

Curtis, A. R.: Discussion of A statistical model for water vapour absorption by R. M. Goody, Q. J. Roy. Meteorol. Soc., 78, 638640, 1952.

Davis, S., Hlavka, D., Jensen, E., Rosenlof, K., Yang, Q. O., Schmidt, S., Borrmann, S., Frey, W., Lawson, P., Voemel, H., and Bui, T. P.: In situ and lidar observations of tropopause subvisible cirrus clouds during TC4, J. Geophys. Res., 115, D00J17, doi:10.1029/2009JD013093, 2010.

Deshler, T., Hofmann, D. J., Johnson, B. J., and Rozier, W. R.: Balloon-borne measurements of the Pinatubo aerosol size distribution and volatility at Laramie, Wyoming during the summer of 1991, Geophys. Res. Lett., 19, 199-202, 1992.

Deshler, T., Johnson, B. J., and Rozier, W. R.: Balloonborne measurements of Pinatubo aerosol during 1991 and 1992 at 41 degrees $\mathrm{N}$ - Vertical profiles, size distribution, and volatility, Geophys. Res. Lett., 20, 1435-1438, 1993.

Dudhia, A.: RFM Software User's Manual, Department of Atmospheric, Oceanic and Planetary Physics, University of Oxford, United Kingdom, available at: http://www.atm.ox.ac.uk/RFM, last access: 12 November 2013.

Dudhia, A., Morris, P. E., and Wells, R. J.: Fast monochromatic radiative transfer calculations for limb sounding, J. Quant. Spectrosc. Radiat. Transfer, 74, 745-756, 2002.

Echle, G., von Clarmann, T., and Oelhaf, H.: Optical and microphysical parameters of the Mt. Pinatubo aerosol as determined from MIPAS-B mid-IR limb emission spectra, J. Geophys. Res., 103, 19193-19211, 1998.

Farlow, N. H., Oberbeck, V. R., Snetsinger, K. G., Ferry, G. V., Polkowski, G., and Hayes, D. M.: Size distributions and mineralogy of ash particles in the stratosphere from eruptions of Mount St. Helens, Science, 211, 832-834, doi:10.1126/science.211.4484.832, 1981.

Fischer, H., Birk, M., Blom, C., Carli, B., Carlotti, M., von Clarmann, T., Delbouille, L., Dudhia, A., Ehhalt, D., Endemann, M., Flaud, J. M., Gessner, R., Kleinert, A., Koopman, R., Langen, J., López-Puertas, M., Mosner, P., Nett, H., Oelhaf, H., Perron, G., Remedios, J., Ridolfi, M., Stiller, G., and Zander, R.: MIPAS: an instrument for atmospheric and climate research, Atmos. Chem. Phys., 8, 2151-2188, doi:10.5194/acp-8-2151-2008, 2008.

Frey, W., Borrmann, S., Kunkel, D., Weigel, R., de Reus, M., Schlager, H., Roiger, A., Voigt, C., Hoor, P., Curtius, J., Krämer, M., Schiller, C., Volk, C. M., Homan, C. D., Fierli, F., Di Donfrancesco, G., Ulanovsky, A., Ravegnani, F., Sitnikov, N. M., Viciani, S., D’Amato, F., Shur, G. N., Belyaev, G. V., Law, K. S., and Cairo, F.: In situ measurements of tropical cloud properties in the West African Monsoon: upper tropospheric ice clouds, Mesoscale Convective System outflow, and subvisual cirrus, Atmos. Chem. Phys., 11, 5569-5590, doi:10.5194/acp-11-55692011, 2011.

Gangale, G., Prata, A. J., and Clarisse, L.: The infrared spectral signature of volcanic ash determined from high-spectral resolution satellite measurements, Remote Sens. Environ., 114, 414-425, doi:10.1016/j.rse.2009.09.007, 2010.

Godson, W. L.: The evaluation of infra-red radiative fluxes due to atmospheric water vapour, Q. J. Roy. Meteorol. Soc., 79, 367$379,1953$.

Gordley, L. L. and Russell, J. M.: Rapid inversion of limb radiance data using an emissivity growth approximation, Appl. Optics, 20, 807-813, 1981.

Grainger, R. G., Lambert, A., Taylor, F. W., Remedios, J. J., Rodgers, C. D., Corney, M., and Kerridge, B. J.: Infrared-absorption by volcanic stratospheric aerosols observed by ISAMS, Geophys. Res. Lett., 20, 1283-1286, doi:10.1029/93GL00823, 1993.

Grainger, R. G., Peters, D. M., Thomas, G. E., Smith, A. J. A., Siddans, R., Carboni, E., and Dudhia, A.: Measuring Volcanic Plume and Ash Properties from Space, in: Remote-sensing of Volcanoes and Volcanic Processes: Integrating Observation and Modelling, edited by: Pyle, D., Mather, T., and Biggs, J., The Geological Society Special Publication 380, doi:10.1144/SP380.7, 2013.

Griessbach, S.: Clouds and aerosol in infrared radiative transfer calculations for the analysis of satellite observations, vol. 139 of Schriften des Forschungszentrums Jülich, Reihe Energie \& Umwelt, Forschungszentrum Jülich, Jülich, available at: http:// juwel.fz-juelich.de:8080/dspace/handle/2128/4597 (last access: 12 November 2013), ISBN 978-3-89336-785-6, 2012.

Griessbach, S., Hoffmann, L., von Hobe, M., Müller, R., Spang, R., and Riese, M.: A six-year record of volcanic ash detection with Envisat MIPAS, in: Proceedings of ESA ATMOS 2012, European Space Agency, ESA Special Publication SP-708 (CDROM), 2012.

Griessbach, S., Hoffmann, L., Hoepfner, M., Riese, M., and Spang, R.: Scattering in infrared radiative transfer: A comparison between the spectrally averaging model JURASSIC and the lineby-line model KOPRA, J. Quant. Spectrosc. Radiat. Transfer, 27, 102-118, doi:10.1016/j.jqsrt.2013.05.004, 2013.

Grimsdell, A. W., Alexander, M. J., May, P. T., and Hoffmann, L.: Model study of waves generated by convection with direct validation via satellite, J. Atmos. Sci., 67, 1617-1631, 2010.

Hoffmann, L.: Schnelle Spurengasretrieval für das Satellitenexperiment Envisat MIPAS, Tech. Rep. JUEL-4207, Forschungszentrum Jülich, Germany, ISSN 0944-2952, 2006.

Hoffmann, L. and Alexander, M. J.: Retrieval of stratospheric temperatures from Atmospheric Infrared Sounder radiance measurements for gravity wave studies, J. Geophys. Res., 114, D07105, doi:10.1029/2008JD011241, 2009.

Hoffmann, L., Spang, R., Kaufmann, M., and Riese, M.: Retrieval of CFC-11 and CFC-12 from Envisat MIPAS observations by means of rapid radiative transfer calculations, Adv. Space Res., 36, 915-921, 2005.

Hoffmann, L., Kaufmann, M., Spang, R., Müller, R., Remedios, J. J., Moore, D. P., Volk, C. M., von Clarmann, T., and Riese, M.: Envisat MIPAS measurements of CFC-11: retrieval, validation, and climatology, Atmos. Chem. Phys., 8, 3671-3688, doi:10.5194/acp-8-3671-2008, 2008.

Hoffmann, L., Weigel, K., Spang, R., Schroeder, S., Arndt, K., Lehmann, C., Kaufmann, M., Ern, M., Preusse, P., Stroh, F., and Riese, M.: CRISTA-NF measurements of water vapor during the SCOUT-O3 Tropical Aircraft Campaign, Adv. Space Res., 43, 74-81, 2009. 
Höpfner, M. and Emde, C.: Comparison of single and multiple scattering approaches for the simulation of limb-emission observations in the mid-IR, J. Quant. Spectrosc. Radiat. Transfer, 91, 275-285, 2005.

Höpfner, M., Pitts, M. C., and Poole, L. R.: Comparison between CALIPSO and MIPAS observations of polar stratospheric clouds, J. Geophys. Res., 114, D00H05, doi:10.1029/2009JD012114, 2009.

Hummel, J. R., Shettle, E. P., and Longtin, D. R.: A New Background Stratospheric Aerosol Model for Use in Atmospheric Radiation Models, AFGL-TR-88-0166, Air Force Geophysics Laboratory, Hanscom AFB, MA, 1988.

Hurley, J., Dudhia, A., and Grainger, R. G.: Retrieval of macrophysical cloud parameters from MIPAS: algorithm description, Atmos. Meas. Tech., 4, 683-704, doi:10.5194/amt-4-683-2011, 2011.

Iwasaki, S., Maruyama, K., Hayashi, M., Ogino, S.-Y., Ishimoto, H., Tachibana, Y., Shimizu, A., Matsui, I., Sugimoto, N., Yamashita, K., Saga, K., Iwamoto, K., Kamiakito, Y., Chabangborn, A., Thana, B., Hashizume, M., Koike, T., and Oki, T.: Characteristics of aerosol and cloud particle size distributions in the tropical tropopause layer measured with optical particle counter and lidar, Atmos. Chem. Phys., 7, 3507-3518, doi:10.5194/acp7-3507-2007, 2007.

Kleinert, A., Aubertin, G., Perron, G., Birk, M., Wagner, G., Hase, F., Nett, H., and Poulin, R.: MIPAS Level 1B algorithms overview: operational processing and characterization, Atmos. Chem. Phys., 7, 1395-1406, doi:10.5194/acp-7-13952007, 2007a.

Kleinert, A., Birk, M., Wagner, G., and Friedl-Vallon, F.: radiometric accuracy of MIPAS calibrated spectra, in: Proceedings Envisat Symposium 2007, European Space Agency, ESA SP-636, 2007b.

Klüser, L., Erbertseder, T., and Meyer-Arnek, J.: Observation of volcanic ash from Puyehue-Cordón Caulle with IASI, Atmos. Meas. Tech., 6, 35-46, doi:10.5194/amt-6-35-2013, 2013.

Krämer, M., Schiller, C., Afchine, A., Bauer, R., Gensch, I., Mangold, A., Schlicht, S., Spelten, N., Sitnikov, N., Borrmann, S., de Reus, M., and Spichtinger, P.: Ice supersaturations and cirrus cloud crystal numbers, Atmos. Chem. Phys., 9, 3505-3522, doi:10.5194/acp-9-3505-2009, 2009.

Lambert, A., Grainger, R. G., Remedios, J. J., Rodgers, C. D., Corney, M., and Taylor, F. W.: Measurements of the evolution of the Mt. Pinatubo aerosol cloud by ISAMS, Geophys. Res. Lett., 20, 1287-1290, doi:10.1029/93GL00827, 1993.

Lambert, A., Grainger, R. G., Rodgers, C. D., Taylor, F. W., Mergenthaler, J. L., Kumer, J. B., and Massie, S. T.: Global evolution of the Mt Pinatubo volcanic aerosols observed by the infrared limb-sounding instruments CLAES and ISAMS on the Upper Atmosphere Research Satellite, J. Geophys. Res., 102, 1495-1512, doi:10.1029/96JD00096, 1997.

Lawson, R. P., Pilson, B., Baker, B., Mo, Q., Jensen, E., Pfister, L., and Bui, P.: Aircraft measurements of microphysical properties of subvisible cirrus in the tropical tropopause layer, Atmos. Chem. Phys., 8, 1609-1620, 2008,

http://www.atmos-chem-phys.net/8/1609/2008/.

Marshall, B. T., Gordley, L. L., and Chu, D. A.: BANDPAK: Algorithms for Modeling Broadband Transmission and Radiance, J. Quant. Spectrosc. Radiat. Transfer, 52, 581-599, 1994.
Massie, S. T., Gille, J. C., Edwards, D. P., Bailey, P. L., Lyjak, L. V., Craig, C. A., Cavanaugh, C. P., Mergenthaler, J. L., Roche, A. E., Kumer, J. B., Lambert, A., Grainger, R. G., Rodgers, C. D., Taylor, F. W., Russell, J. M., Park, J. H., Deshler, T., Hervig, M. E., Fishbein, E. F., Waters, J. W., and Lahoz, W. A.: Validation studies using multiwavelength cryogenic limb array etalon spectrometer (CLAES) observations of stratospheric aerosol, J. Geophys. Res., 101, 9757-9773, doi:10.1029/95JD03225, 1996.

Mendrok, J., Schreier, F., and Höpfner, M.: Estimating cirrus cloud properties from MIPAS data, Geophys. Res. Lett., 34, L08807, doi:10.1029/2006GL028246, 2007.

Mossop, S.: Volcanic dust collected at altitude of $20 \mathrm{~km}$, Nature, 203, 824-827, doi:10.1038/203824a0, 1964.

Murrow, P. J., Rose, W. I., and Self, S.: Determination of the total grain-size distribution in a vulcanian eruption column, and its implications to stratospheric aerosol perturbation, Geophys. Res. Lett., 7, 893-896, doi:10.1029/GL007i011p00893, 1980.

NASA Earth Observatory: available at: http://earthobservatory.nasa. gov/IOTD/view.php?id=51057 (last access: 12 November 2013), 2013.

NASA MODIS: available at: http://rapidfire.sci.gsfc. nasa.gov/cgi-bin/imagery/single.cgi?image=crefl1_143.

A2011157142500-2011157143000.2km.jpg (last access: 12 November 2013), 2013.

NASA OMI: available at: http://ozoneaq.gsfc.nasa.gov/ OMIAerosol.md (last access: 12 November 2013), 2013.

Offermann, D., Grossmann, K.-U., Barthol, P., Knieling, P., Riese, M., and Trant, R.: Cryogenic Infrared Spectrometers and Telescopes for the Atmosphere (CRISTA) experiment and middle atmosphere variability, J. Geophys. Res., 104, 16311-16325, 1999.

Pollack, J., Toon, O., and Khare, B.: Optical properties of some terrestrial rocks and glasses, Icarus, 19, 372-389, doi:10.1016/0019-1035(73)90115-2, 1973.

Prata, A.: Observations of volcanic ash clouds in the 10-12-mu-m window using AVHRR/2 data, Int. J. Remote Sens., 10, 751-761, 1989a.

Prata, A.: Infrared radiative-transfer calculations for volcanic ash clouds, Geophys. Res. Lett., 16, 1293-1296, doi:10.1029/GL016i011p01293, 1989 b.

Prata, A. and Grant, I.: Retrieval of microphysical and morphological properties of volcanic ash plumes from satellite data: Application to Mt Ruapehu, New Zealand, Q. J. Roy. Meteorol. Soc., 127, 2153-2179, doi:10.1002/qj.49712757615, 2001.

Prata, F., Bluth, G., Rose, B., Schneider, D., and Tupper, A.: Failures in detecting volcanic ash from a satellite-based technique - Comments, Remote Sens. Environ., 78, 341-346, doi:10.1016/S00344257(01)00231-0, 2001.

Pruppacher, H. R. and Klett, J. D.: Microphysics of clouds and precipitation, Springer, Dordrecht, 2nd Edn., 2010.

Pueschel, R., Russell, P., Allen, D., Ferry, G., Snetsinger, K., Livingston, J., and Verma, S.: Physical and optical-properties of the Pinatubo volcanic aerosol - aircraft observations with impactors and a sun-tracking photometer, J. Geophys. Res., 99, 1291512922, doi:10.1029/94JD00621, 1994.

Remedios, J. J., Leigh, R. J., Waterfall, A. M., Moore, D. P., Sembhi, H., Parkes, I., Greenhough, J., Chipperfield, M. P., and Hauglustaine, D.: MIPAS reference atmospheres and comparisons to V4.61/V4.62 MIPAS level 2 geophysical data sets, At- 
mos. Chem. Phys. Discuss., 7, 9973-10017, doi:10.5194/acpd-79973-2007, 2007.

Ridolfi, M., Carli, B., Carlotti, M., von Clarmann, T., Dinelli, B., Dudhia, A., Flaud, J., Hopfner, M., Morris, P., Raspollini, P., Stiller, G., and Wells, R.: Optimized forward model and retrieval scheme for MIPAS near-real-time data processing, Appl. Optics, 39, 1323-1340, doi:10.1364/AO.39.001323, 2000.

Riese, M., Spang, R., Preusse, P., Ern, M., Jarisch, M., Offermann, D., and Grossmann, K. U.: Cryogenic Infrared Spectrometers and Telescopes for the Atmosphere (CRISTA) data processing and atmospheric temperature and trace gas retrieval, J. Geophys. Res., 104, 16349-16367, 1999.

Rothman, L. S., Gordon, I. E., Barbe, A., Benner, D. C., Bernath, P. E., Birk, M., Boudon, V., Brown, L. R., Campargue, A., Champion, J. P., Chance, K., Coudert, L. H., Dana, V., Devi, V. M., Fally, S., Flaud, J. M., Gamache, R. R., Goldman, A., Jacquemart, D., Kleiner, I., Lacome, N., Lafferty, W. J., Mandin, J. Y., Massie, S. T., Mikhailenko, S. N., Miller, C. E., Moazzen-Ahmadi, N., Naumenko, O. V., Nikitin, A. V., Orphal, J., Perevalov, V. I., Perrin, A., Predoi-Cross, A., Rinsland, C. P., Rotger, M., Simeckova, M., Smith, M. A. H., Sung, K., Tashkun, S. A., Tennyson, J., Toth, R. A., Vandaele, A. C., and Vander Auwera, J.: The HITRAN 2008 molecular spectroscopic database, J. Quant. Spectrosc. Radiat. Transfer, 110, 533-572, 2009.

Sawamura, P., Vernier, J. P., Barnes, J. E., Berkoff, T. A., Welton, E. J., Alados-Arboledas, L., Navas-Guzman, F., Pappalardo, G., Mona, L., Madonna, F., Lange, D., Sicard, M., Godin-Beekmann, S., Payen, G., Wang, Z., Hu, S., Tripathi, S. N., CordobaJabonero, C., and Hoff, R. M.: Stratospheric AOD after the 2011 eruption of Nabro volcano measured by lidars over the Northern Hemisphere, Environ. Res. Lett., 7, 034013, doi:10.1088/17489326/7/3/034013, 2012.

Schumann, U., Weinzierl, B., Reitebuch, O., Schlager, H., Minikin, A., Forster, C., Baumann, R., Sailer, T., Graf, K., Mannstein, H., Voigt, C., Rahm, S., Simmet, R., Scheibe, M., Lichtenstern, M., Stock, P., Rüba, H., Schäuble, D., Tafferner, A., Rautenhaus, M., Gerz, T., Ziereis, H., Krautstrunk, M., Mallaun, C., Gayet, J.F., Lieke, K., Kandler, K., Ebert, M., Weinbruch, S., Stohl, A., Gasteiger, J., Olafsson, H., and Sturm, K.: Airborne observations of the Eyjafjalla volcano ash cloud over Europe during air space closure in April and May 2010, Atmos. Chem. Phys. Discuss., 10, 22131-22218, doi:10.5194/acpd-10-22131-2010, 2010.

Sembhi, H., Remedios, J., Trent, T., Moore, D. P., Spang, R., Massie, S., and Vernier, J.-P.: MIPAS detection of cloud and aerosol particle occurrence in the UTLS with comparison to HIRDLS and CALIOP, Atmos. Meas. Tech., 5, 2537-2553, doi:10.5194/amt-5-2537-2012, 2012.

Simpson, J. J., Hufford, G., Pieri, D., and Berg, J.: Failures in detecting volcanic ash from satellite-based technique, Remote Sens. Environ., 72, 191-217, doi:10.1016/S0034-4257(99)00103-0, 2000.

Smithonian Global Volcanism Programme, available at: http: //www.volcano.si.edu/volcano.cfm?vn=357150\#June2011 (last access: 12 November 2013), 2013.

Spang, R. and Remedios, J. J.: Observations of a distinctive infrared spectral feature in the atmospheric spectra of polar stratospheric clouds measured by the CRISTA instrument, Geophys. Res. Lett., 30, 1875, doi:10.1029/2003GL017231, 2003.
Spang, R., Riese, M., and Offermann, D.: CRISTA-2 observations of the south polar vortex in winter 1997: A new dataset for polar process studies, Geophys. Res. Lett., 28, 3159-3162, doi:10.1029/2000GL012374, 2001.

Spang, R., Eidmann, G., Riese, M., Offermann, D., Preusse, P., Pfister, L., and Wang, P. H.: CRISTA observations of cirrus clouds around the tropopause, J. Geophys. Res., 107, 8174, doi:10.1029/2001JD000698, 2002.

Spang, R., Remedios, J. J., and Barkley, M. P.: Colour indices for the detection and differentiation of cloud type in infra-red limb emission spectra, Adv. Space Res., 33, 1041-1047, 2004.

Spang, R., Remedios, J. J., Tilmes, S., and Riese, M.: MIPAS observation of polar stratospheric clouds in the Arctic 2002/2003 and Antarctic 2003 winters, in: Atmospheric remote sensing: Earth's surface, troposphere, stratosphere and mesosphere - I, edited by: Burrows, J. P. and Eichmann, K. U., Adv. Space Res., 36, 868878, doi:10.1016/j.asr.2005.03.092, 2005.

Spang, R., Hoffmann, L., Kullmann, A., Olschewski, F., Preusse, P., Knieling, P., Schroeder, S., Stroh, F., Weigel, K., and Riese, M.: High resolution limb observations of clouds by the CRISTANF experiment during the SCOUT-O3 tropical aircraft campaign, Adv. Space Res., 42, 1765-1775, doi:10.1016/j.asr.2007.09.036, 2008.

Spang, R., Arndt, K., Dudhia, A., Höpfner, M., Hoffmann, L., Hurley, J., Grainger, R. G., Griessbach, S., Poulsen, C., Remedios, J. J., Riese, M., Sembhi, H., Siddans, R., Waterfall, A., and Zehner, C.: Fast cloud parameter retrievals of MIPAS/Envisat, Atmos. Chem. Phys. Discuss., 11, 33013-33094, doi:10.5194/acpd-1133013-2011, 2011.

Stiller, G. P.: The Karlsruhe Optimized and Precise Radiative Transfer Algorithm (KOPRA), Tech. Rep. FZKA-6487, Forschungszentrum Karlsruhe, 2000.

Stiller, G. P., von Clarmann, T., Funke, B., Glatthor, N., Hase, F., Höpfner, M., and Linden, A.: Sensitivity of trace gas abundances retrievals from infrared limb emission spectra to simplifying approximations in radiative transfer modelling, Appl. Optics, 41, 249-280, 2002.

Stothers, R. B.: A chronology of annual mean effective radii of stratospheric aerosols from volcanic eruptions during the twentieth century as derived from ground-based spectral extinction measurements, J. Geophys. Res., 106, 32043-32049, doi:10.1029/2001JD000414, 2001.

Tian, L., Heymsfield, G. M., Heymsfield, A. J., Bansemer, A., Li, L. H., Twohy, C. H., and Srivastava, R. C.: A Study of Cirrus Ice Particle Size Distribution Using TC4 Observations, J. Atmos. Sci., 67, 195-216, 2010.

Ungermann, J., Kaufmann, M., Hoffmann, L., Preusse, P., Oelhaf, H., Friedl-Vallon, F., and Riese, M.: Towards a 3-D tomographic retrieval for the air-borne limb-imager GLORIA, Atmos. Meas. Tech., 3, 1647-1665, doi:10.5194/amt-3-1647-2010, 2010.

Volz, F. E.: Infrared optical constants of ammonium sulfate, Sahara dust, volcanic pumice and fly ash, Appl. Optics, 12, 564-568, 1973.

Warren, S. G. and Brandt, R. E.: Optical constants of ice from the ultraviolet to the microwave: A revised compilation, J. Geophys. Res., 113, D14220, doi:10.1029/2007JD009744, 2008.

Weigel, K., Riese, M., Hoffmann, L., Hoefer, S., Kalicinsky, C., Knieling, P., Olschewski, F., Preusse, P., Spang, R., Stroh, F., and Volk, C. M.: CRISTA-NF measurements during the AMMA- 
SCOUT-O3 aircraft campaign, Atmos. Meas. Tech., 3, 14371455, doi:10.5194/amt-3-1437-2010, 2010.

Weinreb, M. P. and Neuendorffer, A. C.: Method to apply homogeneous-path transmittance models to inhomogenous atmospheres, J. Atmos. Sci., 30, 662-666, 1973.
Wen, S. and Rose, W. I.: Retrieval of sizes and total masses of particles in volcanic clouds using AVHRR bands 4 and 5, J. Geophys. Res., 99, 5421-5431, doi:10.1029/93JD03340, 1994. 